\title{
SÍNTESIS Y ANÁLISIS EN LAS LENGUAS. \\ CRÍTICA DE LA TIPOLOGÍA MORFOLÓGICA CLÁSICA Y DE ALGUNAS DE SUS APLICACIONES SINCRÓNICAS Y DIACRÓNICAS
}

\author{
Juan Carlos Moreno Cabrera \\ Universidad Autónoma de Madrid \\ juancarlos.moreno@uam.es
}

\begin{abstract}
Resumen
The classical morphological classification of languages into three types (isolating, agglutinating and inflectional) was interpreted in the nineteenth century as indicative of three stages of language evolution. It was assumed that the inflectional type was the more evolved stage in language development. Although this classification is still in use in the current linguistic literature, no linguist appears to maintain explicitly that interpretation. Nonetheless, there are some recent proposals in which some version of that interpretation is assumed. In this paper two of these proposals are critically analized. The first consists in McWhorter's (2001) statement that the grammar of creoles are the simplest grammars. The second is Alinei's (1996) contention that the three language types correlate with the prehistoric development of tool-making. It is shown that the points made by both McWhorter and Alinei are ethnocentrically biased and lack a sound linguistic basis.
\end{abstract}

\section{Aislamiento, aglutinación y flexión en la clasificación lingüística}

Es habitual encontrar en los manuales de lingüística modernos la clasificación morfológica decimonónica de las lenguas según la cual los idiomas del mundo pertenecen a uno de los siguientes tipos: aislante, aglutinante y flexivo o fusionante. A ellos se añaden habitualmente el tipo incorporante (propuesto por Humboldt') y el polisintético ${ }^{2}$.

Por ejemplo, en Gallardo Paúls (2000: 146-150), García Miguel (2000: 194-197) y Moure (2001: 24-26) encontramos expuesta esta clasificación tipológica con ejemplos ilustrativos, tal como se hace en los manuales relevantes publicados en el extranjero.

Por supuesto, ya hoy en día no se expresa de modo explícito el punto de vista de Humboldt, adoptado luego por Schleicher ${ }^{3}$, de que estos tipos de lengua reflejan estadios

\footnotetext{
1 En el número \$29a de Humboldt 1830-1835 (páginas 528-544 de Humboldt 1994 y páginas 184-202 de la versión española de 1990) Humboldt habla del Einverleibungssystem ser Sprachen traducido en la versión española citada como sistema incorporativo de las lenguas y se analiza el fenómeno de la incorporación nominal en el nahua.

2 Denominadas así por Sapir (1921: 123).

3 Tal como hemos señalado y revisado críticamente en Moreno Cabrera (1995: 102-103) y Moreno Cabrera (2000b: 93-96). Sobre las clasificaciones lingüísticas del siglo XIX se puede consultar las dos excelentes visiones de conjunto de A. Morpurgo Davis (1975 y 1998).
}

ELUA, 17, 2003, págs. 465-504 
evolutivos del lenguaje humano, siendo el estadio más primitivo el representado por las lenguas aislantes y el más evolucionado, el representado por las lenguas flexivas. Si adoptamos esta idea hemos de deducir absurdos como el siguiente: ya que el anglosajón o inglés antiguo es una lengua predominantemente flexiva ${ }^{4}$ y el inglés moderno es una lengua marcadamente aislante, hemos de deducir que el inglés moderno es una lengua más primitiva que el inglés antiguo. $O$ como el siguiente: ya que el esquimal es una lengua polisintética y el inglés moderno es una lengua predominantemente aislante, el esquimal es una lengua más evolucionada que el inglés moderno.

He dicho que este punto de vista ha dejado de expresarse de modo explícito, pero esto no quiere decir que haya sido abandonado. Como veremos en las secciones siguientes, dicho punto de vista etnocéntrico está detrás de algunas de las afirmaciones que se hacen en la actualidad sobre, por ejemplo, las lenguas criollas.

Merece la pena citar aquí las siguientes palabras de los lingüistas alemanes von Stechow y W. Geuder:

Wir möchten zeigen, daß die Erstellung der genauen Satzbedeutung in allen Sprachen in der gleichen Weise von abstrakten, unsichtbaren Operationen abhängig ist, die hinter der sprachlichen Oberfläche ablaufen; die Existenz von morphologischen Markierungen ersetzt diese Konstruktionsarbeit nicht, weil sehr häufig die Information nicht an der Stelle sichtbar gemacht wird, wo sie logisch hingehört ${ }^{5}$ (von Stechow \& Geuder, 1997: 3).

En efecto, es un principio establecido en la lingüística actual que las lenguas no son totalmente explícitas desde el punto de vista de la realización morfosintáctica de todas sus operaciones $^{6}$.

Este principio debe llevarnos a desconfiar de todos aquellos juicios sobre las lenguas que se basan en un examen morfológico de las mismas, dado que ninguna lengua refleja todas sus características morfosintácticas en la morfología y, lo que es más importante aún, no hay dos lenguas que expresen exactamente las mismas propiedades morfosintácticas mediante su morfología ${ }^{7}$.

Un trabajo importante respecto de la tipología morfológica de las lenguas, que ha tenido una indudable repercusión en las consideraciones sobre los tipos lingüísticos morfológicos, es el publicado por Greenberg sobre el enfoque cuantitativo de dicha tipología (Greenberg, 1954).

Greenberg menciona al principio de este trabajo la tipología morfológica decimonónica y hace referencia a la propuesta de Sapir (1921) en la que la tricotomía mencionada se sustituye por la tricotomía analítico, sintético y polisintético. Greenberg nota que Sapir rechazó las interpretaciones evolutivas o valorativas de la tricotomía decimonónica.

4 Véase la sección novena del presente trabajo.

5 He aquí nuestra traducción de este párrafo: "Quisiéramos mostrar que en todas las lenguas la construcción de un significado oracional preciso depende del mismo modo de operaciones abstractas e invisibles, que se aplican detrás de la superficie lingüística visible. La existencia de marcación morfológica no sustituye este trabajo de construcción, dado que a menudo la información no se hace visible allí donde está lógicamente implicada".

6 Es lo que hemos denominado el principio de la opacidad. Véase Moreno Cabrera (1995: 16 y 1987: 121)

7 Es lo que hemos denominado el principio de la perspectiva. Véase Moreno Cabrera (1995: 21 y 1987: 
Greenberg parte de la propuesta de Sapir y la desarrolla desde una perspectiva gradualista en la que se tiene en cuenta una serie de parámetros que cada lengua realiza en mayor o menor medida.

Greenberg propone unas mediciones que no se basan en simples impresiones subjetivas, sino en un muestreo sobre la base de un corpus textual más o menos amplio. Este autor propone los siguientes índices graduales: índice de síntesis ${ }^{8}$, índice de aglutinación, índice de flexión, índice de composición e índices de prefijación y sufjación?.

A modo de ejemplo, veamos los resultados obtenidos sobre un texto de cien palabras en inglés y esquimal ${ }^{10}$.

\section{Tabla 1}

\begin{tabular}{|l|c|c|}
\hline indice & inglés & esquimal \\
\hline síntesis & 1,68 & 3,72 \\
\hline aglutinación & 0,30 & 0,03 \\
\hline composición & 1,00 & 1,00 \\
\hline prefijación & 0,04 & 0,00 \\
\hline sufijación & 0,64 & 2,72 \\
\hline
\end{tabular}

Más que decir que el esquimal es una lengua polisintética y el inglés una lengua aislante podemos afirmar que el inglés es menos sintético que el esquimal, menos aglutinante, igual de compositivo, más prefijal y menos sufijal que el esquimal en el nivel de la morfología.

Pero ya he dicho que ninguna lengua expresa toda su morfosintaxis en la morfología $\mathrm{y}$, por tanto, de aquí no puede deducirse otra cosa que la idea de que el esquimal es más sintético en su morfología que el inglés, pero en ningún caso que el esquimal es más sintético en general que el inglés. Para determinar esto tendríamos que tener en cuenta todos los aspectos de la morfología y de la sintaxis de ambas lenguas, lo cual es muy difícil, dado que sabemos que hay muchos fenómenos morfológicos y sintácticos que se manifiestan sólo indirectamente y que es muy difícil a veces desentrañar y poner de manifiesto.

A partir de la propuesta de Greenberg, en los manuales es frecuente encontrar la idea de que cada lengua tiene un determinado grado de síntesis y análisis morfológicos. Por ejemplo, Comrie (1981: 48) afirma que existen dos índices fundamentales en la tipología morfológica de las lenguas: el índice de síntesis, que se toma directamente de Greenberg, y el índice de fusión. Esta misma idea es recogida por Whaley (1997: 128-136), quien habla también de un índice de síntesis y de un índice de fusión, siguiendo a Greenberg y Comrie. Se insiste en que estos índices colocan a las lenguas en un continuum y no en una serie de compartimentos estancos.

8 Este índice se obtiene dividiendo el númeto de morfemas por el número de palabras: si cada palabra contiene exactamente un morfema o unidad significativa se obtendrá el valor 1 y la lengua será completamente analítica; cuanto más alejado de esa cifra esté el valor, más sintética es la lengua. Por ejemplo, si en cien palabras hay 300 unidades significativas tendremos un índice de síntesis de 3 .

9 Además de éstos, Greenberg incluye los índices de aislamiento, flexión pura y concordancia, que pueden verse en Moreno Cabrera (1997: 34) y, por supuesto, en el propio artículo de Greenberg.

10 El cuadro siguiente se extrae del cuadro de la página 23 del artículo de Greenberg tal como aparece en la edición consultada. 


\section{Lengua hablada, lengua escrita y clasificación tipológica de las lenguas}

La consideración de la lengua escrita como medio de clasificación tipológica de las lenguas ha sesgado de modo muy pronunciado los criterios que se siguen para decidir cuándo una lengua es predominantemente sintética o analítica desde el punto de vista morfológico.

Normalmente se comparan lenguas que se escriben habitualmente como el inglés o el chino con lenguas que no se escriben habitualmente, como el esquimal. Este tipo de comparación es claramente ilegítima, dado que las convenciones de la ortografía hacen muchas veces que una lengua parezca más analítica de lo que en realidad es. Esto es especialmente así en el caso de la escritura china. Es sabido que en la escritura china los caracteres logográficos se escriben separados sin que en momento alguno se unan mediante trazos aquellos caracteres que corresponden a una única palabra (en todo caso, lo único que puede hacerse es ponerlos más juntos de lo normal). Esta convención nos presenta la lengua china como mucho más analítica de lo que en realidad es, dado que en chino, como en las demás lenguas, en el habla se unen palabras con partículas en unidades fonéticamente inseparables.

Los ejemplos de las lenguas que habitualmente no se escriben se toman del habla $y$, al faltar unas convenciones ortográficas determinadas, se tienden a transcribir esos ejemplos con la trabazón típica de la lengua hablada, lo cual nos lleva a presentar determinadas lenguas como más sintéticas de lo que en realidad son.

Es claro que si comparamos el esquimal hablado con otra lengua, como el español o el chino, hay que hacerlo con el español o chino hablados, no con las versiones escritas de ambos idiomas.

Voy a mostrar estos puntos con unos ejemplos ilustrativos.

Consideremos primero una expresión de una lengua conceptuada como ejemplo típico de idioma polisintético. Se trata del esquimal, lengua en la que es frecuente encontrar verbos holofrásticos, equivalentes a una oración completa en otras lenguas:

(1) Kaipiallrulliniuk

KAIG-PIAR-_LLRU-LLINI-U-K

HAMBRIENTO-REALMENTE-PASADO-AL PARECER-INDIC-AMBOS

'Parecía que ambos tenían hambre de verdad'

Vemos que en una palabra confluyen un buen número de elementos léxicos y morfológicos.

Otro ejemplo de lo mismo lo tenemos en las siguientes oraciones transcritas de una lengua hablada en Costa de Marfil

(2) Expresiones de una lengua de Costa de Marfil
a. /KILKUR/
CONJ-3SG-ANDAR RÁPIDO
b. /KNUKURIÕ/
CONJ-3PL-ANDAR RÁPIDO
c. /LÒMIMARS̆/
DEF-PERSONA-3SG-CAMINA

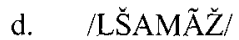
DEF-GATO-DEVORA
e. $/ \check{Z} \mathrm{PO} /$
f. /ŽTLDÒN/
1SG-SER CAPAZ - ISG
1SG-2SG-3SG-ENTREGAR 
En esta lengua observamos también una apreciable acumulación de morfemas en las palabras; cuatro en los casos tercero y sexto. En algún caso, como el quinto parece difícil hacer una separación de los tres morfemas que hay presentes, pues la expresión consta de tres sonidos (dos consonánticos y uno vocálico). Las dos primeras son formas verbales y están en modo conjuntivo (CONJ) y, por tanto se utilizan en la subordinación; se diferencian sólo en el número. La tercera expresión es una oración completa que consta de una parte nominal y otra verbal con deíxis verbal de persona. Lo mismo puede decirse de la expresión $d$ que también consta de una parte nominal y otra verbal y equivale a una oración completa. Las dos últimas formas son verbales y en ellas se expresa mediante deíxis verbal de persona la entidad de la que se predica la acción verbal. Estamos, pues, ante una lengua típicamente exótica de las que a menudo aparecen ejemplos en los manuales de tipología lingüística.

¿De qué lengua se trata? Pues bien es una lengua hablada en África, pero no es una lengua africana, dado que este idioma misterioso algunas de cuyas producciones acabo de enumerar no es otro que el francés, lengua oficial de Costa de Marfil. En el siguiente esquema muestro cómo se relacionan esas formas del francés hablado con las correspondientes del francés escrito.

(3) Ejemplos de francés hablado y escrito ${ }^{11}$
a. KILKUR/
QU'IL COURT
b. /KNUKURIÕ/
QUE NOUS COURIONS
c. /LÒMIMARŠ/
L'HOMME IL MARCHE
d. /LŠAMÃŽ/
e. /ŽPÖ/
LE CHAT MANGE
f. /ŽTLDÒN/
JE PEUX
JE TE LE DONNE

Sería ingenuo pensar que formas de este tipo sólo se encuentran en el francés hablado; en español hablado también encontramos abundamentamente estas construcciones sintéticas:

(4) Síntesis en español hablado
a. PATRÁS
b. PALANTE
c. MELÁNDÀO
d. SAMMPERDÍO
PARA ATRÁS
PARA ADELANTE
ME LO HAN DADO
e. TELANDICHOTÓ
SE HAN PERDIDO
f. ¿ANDANDARÁ?
TE LO HAN DICHO TODO
¿ADÓNDE ANDARÁ?

A la hora de llevar a cabo una tipología morfológica de las lenguas no sólo debemos comparar las lenguas en el mismo nivel (el hablado o el escrito) sino que también debemos manejar unas determinadas unidades morfológicas.

Es sabido que el concepto de palabra es demasiado vago e indeterminado como para poder fundamentar una tipología mínimanente sólida.

Precisamente A. Martinet ( $1985^{12}$ y $1989^{13}$ ) ha llamado la atención sobre unidades morfosintácticas distintas de las palabras tal como se conciben tradicionalmente.

11 Estas transcripciones las da A. Martinet en su conocido manual de lingüística general (Martinet 1960).

12 Especialmente en los números $\$ 3.44$ a $\$ 3.61$.

13 En las páginas 193 a 195. 
Martinet introduce el concepto de sintema ${ }^{14}$ para hacer referencia a las expresiones compuestas de dos o más palabras tradicionales pero que se comportan como un lexema único. Aduce ejemplos como el francés jeune fille 'soltera' o chemin de fer 'ferrocarril' 15; el español dar pie también sería un sintema.

Además, el gran lingüista francés añade a éste el concepto de silema. El silema es aquel sintagma compuesto por un núcleo (monema o sintema) más sus determinantes. Martinet considera silemas palabras declinadas latinas como rosarum o expresiones como el francés les oiseaux, dado que en ellas el núcleo tiene determinantes morfológicos de número, género o caso. El propio Martinet aduce que son las prescripciones ortográficas ${ }^{16}$ lo que impide tradicionalmente ver estos compuestos como unidades.

Sin hacer caso a las convenciones ortográficas podemos ver muy bien una gran similitud entre, por ejemplo, el español a las casas y el vasco etxeetara que traduce al sintagma español.

La expresión española a las casas constituye una clara unidad prosódica que consta de un elemento nuclear, de un determinante y de una preposición. Estos dos elementos no son elementos morfológicamente libres, siempre han de aparecer ligados a un elemento léxico. Si bien podemos concebir casas como una unidad morfológicamente autosuficiente esto no es posible ni con a ni con las ni con a las, que funcionan a todos los efectos como morfemas dependientes de un elemento léxico al que determinan. Por ello, en absoluto sería objetable escribir este sintagma todo junto como un silema unitario: alascasas. Si presentáramos así el español podríamos decir perfectamente que alascasas es el caso adlativo plural definido del sustantivo casa y, por tanto, realizar exactamente el mismo análisis que puedo proponer para el vasco. Obtendríamos, pues un esquema como el siguiente:

(5) Flexión nominal en español y vasco

a. nominativo/absolutivo ${ }^{17}$ indefinido:
b. nominativo/absolutivo definido singular:
c. nominativo/absolutivo definido plural:
d. adlativo indefinido:
e. adlativo definido singular
f. adlativo definido plural

casa/etxe lacasa/etxea ${ }^{18}$ lascasas/etxeak acasa/etxetara alacasa/etxera alascasas/etxeetara

Para observar los efectos de esta propuesta, en la que tengo en cuenta la lengua hablada y no la escrita, vamos a ver qué valores se obtienen al calcular los índices de síntesis en español y en vasco a partir de un texto breve. Compararemos esos valores con los que se obtienen al calcular ese índice sin tener en cuenta las convenciones ortográficas del texto español.

14 Véase Martinet (1985: 52-57 y 1989: 200- 225).

15 Véase Martinet (1985: 122 y 1989: 204-210).

16 Martinet (1989: 207).

17 Como es sabido el vasco es una lengua de morfología casual ergativa, por lo que el caso no marcado que corresponde al nominativo en las lenguas nominativo-acusativas y que se utiliza en el esquema es el absolutivo (opuesto al caso marcado ergativo).

18 Igual que escribimos en español lacasa podría alterar la ortografia del vasco y escribir esta palabra como etxe $a$, es decir, separando el morfema $a$ de definitud tal como hacemos en la ortografía española. Pcro exactamente igual que escribir la separado en la casa no hace que ese la sea un elemento morfológicamente y prosódicamente independiente, tampoco escribir esa $a$ de modo separado haría lo propio con ese morfema vasco. 
El texto en cuestión es un pasaje del Manifiesto del Partido Comunista de Marx y Engels. Doy ahora las dos versiones que tengo en cuenta con un análisis morfológico ${ }^{19}$

\section{TEXTO VASCO}

Ikus-i du-gu no-la aurre-ko gizarte guzti-a-k klase zapal-tzaile eta klase zapaldu-en arte-ko kontras-tasun-a-ren oin-arri-a-n jarri-a-k izan dir-en. Baina klase bat zapal-tze-ko, gutienez, esklabu-tasune-a-n bizi-tze-n uzte-n du-te-n kondizio-a-k segura-tu behar zaiz-ki-o. Feudalismo-a-n ber-tan, jopu-a komunitate bat-en partaide iza-te-ra hel zite-ke-en, feudal absolutismo-a-ren uztarri-pe-an plebeio-a burjer maila-ra hel zite-ke-en beza-la. Lan-gile moderno-a, ordea, industria-ren aurre-ra-pen-a-z igon beharre-a-n, gero eta behe-ra-go eror-tze-n ari da, bai eta bere klase propio-a-ren bizi-modu-a-ren azpi-raino ere. Trabailaria pobrezia-n eror-tze- $n$ da eta gose-a populazio-a eta aberas-tasun-a bera baino arina-go handi-tze-n. Ber-az, argi-ro dago burjeseria ez de-la hon-ez gero gauza klase zuzen-tzailetzat du-en zer-egin-a bete-tze-ko, ez eta giz-arte-a-ri, lege nagusi-tzat, bere klase-a-ren bizi-kondizio-a-k jar-tze-ko ere. Ezin goberna deza-ke, bere esklabu-a-ri, berone-n esklabu-tasun-a-re-kin ados egon daite-ke-en existentzia bat, ezin segura diezai-o-ke-ela-ko, zer-en hura ahul-tze-n utzi behar bai-tu, hala-ko puntu-ta-ra-ino non, esklabu-a elika-tu behar bai-tu har-ta-z elika-tu-a izan beharre-a-n. Giz-arte-a ezin bizi daite-ke gehi-ago har-en zapal-kuntza-pe-a-n, eta ber-on-ek zera esan nahi du, burjeseri-a-ren bizi-tza, aurre-ra-n-tze-an, ezin etor daite-ke-ela bate-ra giz-arte-a-ren bizi-tza-re-kin. (321 monemas y 163 palabras)

\section{TEXTO ESPAÑOL}

Tod-a-s l-a-s socie-dad-es anterior-es como he-mos vis-to, han des-cansa-do en e-l antagonismo entre clase-s opres-or-a-s y oprimid-a-s. Mas para oprimi-ir a un-a clase, es precis-o a-segur-ar-le un-a-s condicion-es que le permit-a-n, por lo menos, arrastr-ar su existencia de esclavi-tud. E-l sierv-o, en plen-o régimen de servi-dumbre, lleg-ó a miembro de la comuna, lo mismo que el pequeñ-o-burgués lleg-ó a elevar-se a l-a categoría de burgués bajo e-l yugo d-e-1 absolut-ismo feudal. E-1 obrer-o modern-o, por e-1 contrari-o, lejos de elevar-se con e-l progreso de 1-a industria, desciend-e siempre más y más por de-bajo de l-a-s condicion-es de vida de su propi-a clase. E-l trabaja-dor ca-e en l-a miseria, y l-a pobre-za crec-e más rápida-mente todavía que l-a pobla-ción y l-a rique-za. Es, pues, evidente que 1-a burguesía ya no es capaz de segu-ir des-empeña-ndo e-l papel de clase domin-ante de 1-a socie-dad ni de im-pon-er a ést-a, como ley regula-dor-a, l-a-s condicion-es de existencia de su clase. No es capaz de a-segur-ar a su esclav-o l-a existen-cia ni siquiera dentro d-e-l marco de 1-a esclavitud, por-que se ve oblig-ad-a a deja-r-l-e de-cae-r hasta e-l punto de ten-er que manten-er-l-e, en lugar de ser manteni-da por é-l. L-a sociedad ya no pued-e vivi-r bajo su domina-ción, l-o que equival-e a deci-r que l-a existen-cia de l-a burgue-sía es, en 1-o sucesiv-o, in-compati-ble con 1-a socie-dad. (353 monemas y 224 palabras)

En el texto vasco tenemos 321 monemas (lexemas y morfemas), que dividido por el número de palabras, que es 163 , nos da un índice de síntesis de 1,9693.

En el texto español tenemos 353 monemas que dividido por el número de palabras, 224, nos da un índice de síntesis de 1,5758 . 
Por tanto, a través de esta comparación, el vasco es una lengua más sintética que el español.

Ahora bien, en vez de contar las palabras ortográficas del texto español, podríamos tener en cuenta las palabras prosódicas, tal como indico en la nueva transcripción de este texto:

\section{TEXTO ESPAÑOL EN TRANSCRIPCIÓN PROSÓDICA}

Todas lassociedades anteriores, comohemosvisto, handescansado enelantagonismo entreclases opresoras yoprimidas. Masparaoprimir aunaclase, espreciso asegurarle unascondiciones quelepermitan, porlomenos, arrastrar suexistencia deesclavitud. Elsiervo, enpleno régimen deservi-dumbre, llegó amiembro delacomuna, lomismo queelpequeñoburgués llegó aelevar-se alacategoría deburgués bajoelyugo delabsolutismo feudal. Elobrero moderno, porelcontrario, lejos deelevarse conelprogreso delaindustria, desciende siempre másymás pordebajo delascondiciones devida desupropia clase. Eltrabajador cae enlamisería, ylapobreza crece másrápidamente todavía quelapoblación ylariqueza. Es, pues, evidente quelaburguesía yanoescapaz deseguir desempeñando elpapel declase dominante delasociedad nideimponer aésta, comoley reguladora, lascondiciones deexistencia desuclase. Noes capaz deasegurar asuesclavo la existencia nisiquiera dentro delmarco delaesclavitud, porque seve obligada adejarle decaer hastaelpunto detener quemantenerle, enlugar desermantenida porél. Lasociedad yanopuede vivir bajosudominación, loque equivale adecir quelaexistencia delaburguesía es, enlosucesivo, incompatible conlasociedad. (353 monemas y 111 palabras)

Ahora el indice de síntesis del español es de $353 / 111=3,1801$. Es decir, considerablemente más alto que el del vasco y el doble que el indice de síntesis calculado sobre el texto en ortografía convencional.

Esto viene a indicarnos que no hay tanta diferencia real entre las lenguas denominadas aglutinantes (como el vasco) y lenguas conceptuadas como flexivas (el español). Se puede decir que español y vasco tienen índices de síntesis similares, dado que con el vasco podemos hacer lo mismo que con el español, es decir, adecuar la ortografía convencional al vasco hablado.

\section{El chino y el vietnamita no son lenguas aislantes ni monosilábicas}

Cuando se habla de lenguas aislantes inmediatamente se ponen como ejemplos típicos el chino y el vietnamita. Se suele decir que estas lenguas son monosilábicas.

Veamos una definición de monosilabismo lingüístico:

En un gran número de lenguas (africanas, asiáticas, americanas) el morfema coincide con la sílaba: en términos corrientes se podría decir que todas su palabras son morfemas: en una estructura de este tipo es difícil (aunque no imposible) que exista una morfología flexiva $y$, por lo tanto, asumen un peso especifico el orden de las palabras y los procedimientos tonales (Cardona, 1988: 187).

Vamos a ver en primer lugar que lo que es monosilábico no es el chino, sino la escritura china y que la idea de que las palabras chinas tienen una sílaba procede de la confusión 
entre palabra y carácter escrito ${ }^{20}$. En chino se distinguen ambas cosas. El término cí (词) significa 'palabra' y el término zi (字) significa 'carácter escrito'.

Por más que se diga que el chino clásico la palabra coincidía con la sílaba, lo cierto es que incluso en chino clásico o antiguo había muchas palabras polisilábicas ${ }^{21}$. En chino moderno las palabras tienen una media de dos sílabas. Por tanto es simplemente errónea la idea de que el chino es o fue una lengua monosilábica. Lo único que puede mantenerse es que a cada carácter chino le corresponde una sílaba y si bien hay palabras que son de una sílaba y se escriben, por tanto, mediante un único carácter, hay muchísimas palabras que al tener más de una sílaba se escriben con dos, tres, cuatro o cinco caracteres. Veamos un ejemplo ilustrativo:

(6) Palabras chinas de dos y tres sílabas
a. 图
b. 图 书
tú 'dibujo'
c. 图 书馆
túshu 'libros'
túshuguân 'librería'

La primera palabra consta de una sillaba y de un solo carácter; la segunda palabra consta de dos sílabas y de dos caracteres y la tercera consta de tres sílabas y de tres caracteres.

Vemos, pues, que los caracteres se corresponden con las sílabas, pero no con las palabras, por lo que no tienen sentido decir que el chino es una lengua de palabras monosilábicas.

Una vez subsanado el error consistente en confundir la escritura con el habla, nos queda por examinar críticamente una segunda idea sobre el chino: que se trata de una lengua aislante.

Veamos un par de definiciones de lengua aislante:

AISLANTES (AMORFAS), lenguas.- Característica de una lengua carente de morfología, sin afijos, en la que las relaciones sintácticas se expresan por yuxtaposición de los distintos elementos radicales (Abraham, 1974: 52).

En las lenguas aislantes la 'oración' está compuesta por elementos simples, comparables a raíces, yuxtapuestos, cuyos valores gramaticales están sólo en función de su localización o de la entonación que se les asigna (Mounin, 1982: 10-11).

Es bastante fácil desmontar estas afirmaciones simplemente mirando un poco de cerca la estructura morfológica de la lengua china. Voy a hacerlo con datos y análisis tomados de Her $2002^{22}$.

Frente a la idea de que en chino no hay morfología, podemos empezar diciendo que se trata de una lengua en la que hay mucha composición morfológica. Veamos tres ejem$\operatorname{plos}^{23}$ :

20 Así lo indica expresamente Mair (1996: 202).

21 Asi lo dice Mair (1996: 202).

22 En este trabajo se utilizan caracteres complejos que he sustuido por los correspondientes simplificados. En cuanto a la transcripción fonética, utilizo a para el tono primero, $a$ para el tono segundo, â para el tono tercero y à para el tono cuarto.

23 Her (2002: 14 y 260$)$. 
(7) Dos palabras compuestas chinas
a. 电话 部虚
diànhuàbù 'guía de teléfono'. Palabra compuesta por diàn (eléctrico) huà (habla) y bù (cuaderno).
b. 卫生错
wèishengzhî 'papel higiénico'. Palabra compuesta por wèi (proteger), sheng (hi- giene) y $z h \hat{\imath}$ (papel).
c. JL 童 乐 国
értónglèyuán 'parque de atracciones'. Palabra compuesta de $儿$ 裏 értóng 'niño' [ a su vez de J ér 'hijo'y 童 tóng 'niño'] y de 乐 四 lèyuán 'paraíso' [de 缼 lè 'alegría' y $y u a ́ n$ 'parque'].

Palabras compuestas como éstas no constituyen elementos formados de raíces yuxtapuestas independientes, tal como quiere hacernos ver una de las definiciones de lengua aislante antes vista. Además podemos comprobar cómo lo que en español son sintagmas (guía de teléfono, papel higiénico y parque de atracciones) en chino es una única palabra, lo cual muestra que la morfología derivativa está en este aspecto más desarrollada en chino que en español.

Veamos una prueba irrefutable de esto aportada por Her (2002: 59). Consideremos los términos huôche 'tren' compuesto de $\nprec$ huô 'fuego' y 车 che 'vehículo' y qiche ' automóvil', compuesto de 秌 qì 'humo' y 车 che 'vehículo'. Estas dos palabras compuestas son indescomponibles, no son la mera yuxtaposición de dos raíces cada una, como lo muestra el hecho de que no podemos coordinarlas de la siguiente manera:

(8) coordinación intramorfológica imposible en chino:

*炏跟汽年

*huô gen qì che

'tren y automóvil'

Además de composición léxica existe derivación morfológica. Hay elementos morfemáticos que se utilizan para crear, por ejemplo, adjetivos. He aquí unos ejemplos ${ }^{24}$.

(9) Derivación adjetival en chino: el prefijo kê
a. 可
kêài 'encantador'. De ài 'amar' y el prefijo deverbal kê.
b. पु 录 kêbei 'lamentable'. De bei 'estar triste' y el prefijo deverbal kê.
c. 可 笑 kêxiào 'ridículo'. De xiào 'reírse' y el prefijo deverbal kê.
d. 可 行 kêxing 'factible', 行 xíng 'hacer'
e. 可 寻
kêwù 'detestable' de 
(10) Derivación nominal en chino: el prefijo 自 zì 'auto'25
a. 自 传 zizhuàn 'autobiografía'. De 传 zhuàn 'biografía'
b. 自 制 zìzhì 'autocontrol'. De zì + 制 zhì 'control'
c. 自 动
zidòng 'automático'. De zì + 动 'mover'

(11) Derivación nominal en chino ${ }^{26}$
a. 作 者
zuòzhê 'autor'. De zuò 'escribir'+ zhê = nominalizador
b. 读者
dúzhê 'lector'. De du' 'leer' + zhê = nominalizador
c. 工人
gongrén 'obrero'. De gong 'trabajo' + rén 'persona' (aquí, sufijo de agente).
d. 马车夫
mâchefu 'cochero'. De mâ 'caballo' che 'carro' fu 'hombre' (aquí, sufijo de agente).
e. 眼 力
yânlì 'vista'. De yân 'ojo' + lì sufijo nominalizador de cualidad.
f. 人加
réniì 'mano de obra'. De rén 'hombre' + li sufijo nominalizador de cualidad.

(12) Derivación adverbial en chino con el sufijo 地 $d e^{27}$
a. 㷊 情 地
rèqíngde 'cordialmente'
b. 自由地
ziuyóude 'libremente'
c. 喍地
shenshende 'profundamente'

Hay también en chino fenómenos de fusión morfonológica en los que un afijo se ve fonológicamente integrado en una palabra y ya no se reconoce como morfema independiente. Es lo que ha ocurrido con el sufijo J ér (escrito en ortografía compleja 兒). Este afijo era originariamente un sufijo diminutivo ${ }^{28}$ pero se ha extendido y ha perdido ese valor fundiéndose con la palabra a que afecta. He aquí algunos ejemplos:

(13) El afijo fusionado Јl ér
a. 狗儿
gôur 'perro' de 猗 gôu 'perro'
b. 事了L
'asunto' de 事 shì 'asunto'
c. 放儿
zhèr 'aquí de 趇 zhè 'aquí' 
El sufijo 子 zi también se ha fundido con numerosas palabras ${ }^{29}$ :

(14) El afijo fusionado 子 $\mathrm{zi}$
a. 本子
bênzi 'cuaderno'. De de 本 bên = clasificador para libros
b. 个子
gèzi 'estatura'. De $\uparrow$ gè $=$ clasificador general

El sufijo 头 tou se integra como parte de diversos lexemas monosílabos, para formar un sustantivo de dos sílabas:

(15) El afijo fusionado 状 tou
a. 木头
mùtou 'madera'. De 木 mù 'madera'
b. 念头
niàntou 'idea'. De 念 niàn 'pensar'
c. 外头
wàitou 'fuera'. De 外 wài 'fuera'

Estos afijos fusionados se pueden combinar en una misma palabra, como por ejemplo 王头儿 shitóur 'piedra', de 石 shí 'piedra'.

Quienes afirman que el chino desconoce los términos puros de relación sintáctica yerran de plano. Existen varias decenas de particulas chinas que expresan relaciones sintácticas puras. Como no puedo examinarlas todas aquí, voy a poner como ejemplo la partícula 的 de. Esta palabra china se suele identificar como particula estructural y tiene una función adjetivadora (sirve para formar complementos del nombre y oraciones adjetivales) y pronominal. Así, por ejemplo 他 的 tade significa 'de él, suyo', 我 们 的 wômende significa 'de nosotros, nuestro' y 中 国 的 zhongguóde quiere decir 'de china, chino'. Tiene función pronominal cuando falta el núcleo: 打鱼 的 dâyúde 'pescador', literalmente: el (hombre) captura-peces. Sirve también para formar oraciones adjetivas como en:

(16) Oración adjetiva en chino $^{30}$

\section{你用的铜笔}

nî yòng de gangbî $=$ tu $+u s a r+d e+p l u m a$

'la pluma con que escribes'

Además, como observa Her (2002: 232-233), la determinación adjetiva puede hacerse con la partícula de o sin ella, de modo que tenemos 新 书 $x i n s h u$ 'nuevo libro' frente a

新 的 书 $x$ in de shu 'libro nuevo'. En el primer caso podemos hablar de un compuesto adjetivo-nombre, pero en el segundo caso estamos ante un sintema.

Pero hay ocasiones en las que estamos ante un compuesto morfológico que no admite 'sintematización' alguna mediante la partícula de. He aquí algunos ejemplos: 
(17) Compuestos modificativo chinos que no admiten 'sintematización'
a. 美 术
*羞的术
mêishù
*mêi de shù
'bellas artes'
b. 圆 规
yuángui
'compás'

\section{*圆 的 规 \\ *yuán de gui}

Estos ejemplos son muy reveladores, porque muestran que la partícula de es un claro elemento relatorio que no puede introducirse cuando estamos ante un auténtico compuesto modificativo adjetival. Esto significa que, por ejemplo, 美 术 mêishì es una palabra indescomponible y no una mera unión de dos raíces yuxtapuestas. Además prueban que la partícula de relaciona dos palabras en un sintema donde hay una clara subordinación sintáctica y no una mera yuxtaposición, tal como reza la definición de lengua aislante que vimos al principio de esta sección.

De todo lo anterior se deduce que el chino no es una lengua aislante ni monosilábica y sí conoce la morfología.

Si a la luz de estas consideraciones comparamos el chino con el alemán, veremos las dos lenguas más próximas de lo que pudiera parecer a primera vista.

Voy a comparar dos palabras compuestas: una del alemán y otra del chino:

(18) Dos palabras compuestas

a. Untersuchungsausschuß 'comisión de investigación'

b. 其 产 Hèn Gòngchângdângyuán 'comunista'

Si analizamos las dos palabras desde la escritura veremos unas diferencias muy grandes, pero si las analizamos desde el punto de vista de la lengua hablada, la cosa cambia. Se trata de dos palabras compuestas. Veremos que su análisis revela similitudes importantes. La palabra alemana consta de dos partes Untersuchungs 'investigación' y Ausschuß 'comisión'; por su parte, la palabra china consta también de dos partes: gòngchăngdâng 'partido comunista' y yuán 'miembro'. En ambos casos la segunda parte constituye el núcleo y la primera es el modificador: comisión de investigación y miembro del partido comunista. Por su parte gòngchăngdâng se compone de gòngchăng 'comunista' y dâng 'partido', que es de nuevo una estructura modificativa.

El término alemán Untersuchungs es la forma genitiva de Untersuchung, que a su vez se deriva de Untersuchen 'investigar'. Este verbo a su vez se compone de unter 'debajo' y suchen 'buscar', a su vez derivado de la raíz such. Por su parte, el término Ausschuß deriva de la preposición aus y del verbo schießen 'arrojar', de raíz schieß. Este análisis lo hago para poner de manifiesto que la palabra alemana, igual que la china, se reduce a términos de una sola sílaba ${ }^{31}$. En última instancia el monosilabismo es característico de las raíces de las lenguas en general, no solo de las del chino.

A la vista de ejemplos como éstos es difícil mantener que el chino es una lengua aislante que no tiene morfología. 
Paso ahora a examinar brevemente el vietnamita, que es otra de las lenguas que se ponen como ejemplo paradigmático de lengua aislante. Los ejemplos son de Chình (1970).

La idea de que el vietnamita es una lengua monosilábica es muy fácil de rebatir; basta con señalar palabras de más de una sílaba. He aquí unas cuantas ${ }^{32}$.

(19) Palabras plurisilábicas en vietnamita

a. đu·o: $i-u \cdot o \cdot i$ 'orangután'

b. to-lo--mo' 'somnoliento'

c. khập-khà-khập-khiễng 'renqueando'

d. bô-lô-ba-la 'atolondrado'

Como ocurre en chino y según observa Chình (1970: 3), las palabras más habituales en vietnamita constan de dos sílabas. A propósito de la palabra $đ u \cdot o \cdot i-u \cdot o \cdot i$ aducida antes, dice Chính (1970: 7) que si separamos las dos sílabas de la misma: $\bar{d} u o: i \mathrm{y}-u \cdot o \cdot i$, obtenemos dos elementos que no tienen significación alguna y que no se emplean nunca solos en la lengua; son, por tanto, partes constituyentes de una única palabra. Lo mismo cabe decir de la palabra tetrasilábica bô-lô-ba-la dado que, si separamos sus sílabas, obtenemos unidades sin significación alguna. Por tanto, no hay duda de que se trata de una palabra de cuatro sílabas.

Como veíamos en chino, en vietnamita también pueden formarse palabras compuestas complejas tal como chín-sách-båo-hộ-mậu-dịch 'proteccionismo' que consta de chín-sách 'política' y båo-họ-mậu-dịch 'proteger el comercio'.

Existen también muchas palabras en las que se puede identificar un componente léxico monosilábico seguido de una sílaba sin significado alguno, por lo que habría que hablar de palabras compuestas de una raíz significativa y de una extensión de esa raíz. He aquí algunos ejemplos ${ }^{33}$ :

(20) Palabras vietnamitas bisilábicas con extensión de raíz monosilábica

a. rộng-rãi 'vasto'

b. giặc-giã 'guerra'

c. khao-khát 'ansiar'

d. bẩn-thiù 'sucio'

Por ejemplo, en la palabra rộng-rãi el elemento rãi es una extensión fonética de la raíz rộng. En el caso de la palabra vista antes khập-khà-khập-khiễng, la raíz es khiễng y los demás elementos son extensiones asemánticas de esa raíz ${ }^{34}$.

En vietnamita, como en chino, existe una amplia serie de palabras compuestas que denotan la actuación de reglas morfológicas derivativas.

Igualmente encontramos afijos con significación claramente gramatical. Por ejemplo, existe un prefijo vô privativo con el que se pueden formar muchas palabras ${ }^{35}$ : 
(21) Ejemplos de derivación prefijal en vietnamita: el prefijo privativo vô
a. vô-gia đình 'sin familia'
b. vô-nghệ nghiệp 'sin profesión'
c. vô-liêm si 'sin dignidad, sin pudor'
d. vô-lễ 'sin educación'
e. vô-tu· 'imparcial'

Otro ejemplo de derivación morfológica lo tenemos en el prefijo tho , que es un afijo denominal agentivo:

(22) Ejemplos de derivación mediante el prefijo denominal agentivo tho.
a. thọ-mộc 'ebanista'
b. thọ-nề 'albañil'
c. thọ-ngoã 'pizarrero'
d. thợ-rèn 'herrero'
e. thọ-may 'sastre'
f. thợ-cao 'peluquero'
g. thợ-máy 'mecánico'
h. thọ'-dồng-hồ 'relojero'

En vietnamita existen diversos verbos que se usan como auxiliares, es decir, con una función puramente gramatical, aspectual, temporal diatética o modal. He aquí un pequeño inventario de estos auxiliares ${ }^{36}$ :

(23) Verbos auxiliares vietnamitas
a. cho 'dar' se usa para marcar la diátesis benefactiva o malefactiva.
b. $\quad$ du'o.c 'lograr' se usa para marcar el aspecto perfectivo-resultativo.
c. có 'ser' se usa para marcar el modo confirmativo.
d. dang se usa para marcar el tiempo presente.
e. $\quad \bar{a} \tilde{a}$ 'terminar' se usa para marcar el tiempo pasado.
$f$. $\quad$ sẽ se usa para marcar el tiempo futuro.
$g$. bắt se usa para marcar el aspecto incoativo.
h. dang se usa también para marcar el aspecto durativo.
i. hết 'acabar' se usa para marcar el aspecto terminativo.

El hecho de que estos verbos se usen también como verbos principales, no auxiliares, no invalida la existencia de verbos auxiliares que expresan determinaciones gramaticales en esta lengua (lo mismo vale para el chino), ya que, por ejemplo, verbos auxiliares españoles como hacer, dejar, estar, volver, ser, venir o ir se usan también como verbos plenos y no por ello dejamos de reconocerlos como auxiliares cuando funcionan como tales en perífrasis aspectuales, modales o diatéticas. Si lo hacemos así en las lenguas occidentales no se ve por qué no puede aplicarse el mismo criterio a idiomas como el vietnamita o el chino.

Los verbos vietnamitas se flexionan para voz pasiva, tal como vemos en los siguientes ejemplos ${ }^{37}$ : 
(24) Flexión verbal pasiva en vietnamita

a. khen 'felicitar' $\Rightarrow$ đu·ơc khen 'ser felicitado': Giáp đu·ợc khen 'Giap es felicitado'

b. mắng 'regañar' $\Rightarrow$ phåi mắng 'ser regañado': Giáp phåi mắng 'Giap es regañado'

c. dánh 'golpear' $\Rightarrow$ bị dánh 'ser golpeado' Giáp bị dánh 'Giap es golpeado'

La selección de los auxiliares đu'ọc por un lado y phåi o bi de otro depende de si el proceso experimentado por el sujeto pasivo le afecta positiva o negativamente.

Igual que en español, el verbo làm 'hacer' además de usarse como verbo principal se utiliza como auxiliar causativo (Chình 1970: 401): làm gãy 'romper', làm cháy 'quemar', làm sông 'dejar escapar', làm ngã 'tirar, hacer caer'.

En su descripción del vietnamita, Chình (1970: 161-185) estudia lo que denomina palabras vacias. Se trata de partículas discursivas que no tienen valor léxico alguno sino sólo una función sintáctica discursiva. Por ejemplo, la partícula thì sirve para marcar el tópico, tal como vemos en la siguiente oración ${ }^{38}$ :

\section{(25) Ejemplo de uso de la partícula thi \\ Súcc thì hai ngn'ò’i ngang nhau \\ 'En cuanto a fuerza, las dos personas son iguales'}

La partícula mà indica causa y condición y junto con ella Chình (1970) cita otras treinta partículas más con distintas funciones semánticas y sintácticas que no son verbos con un significado léxico pleno.

Todos estos ejemplos que he dado del chino y del vietnamita muestran claramente que estas lenguas no son aislantes en el sentido de que no se limitan a yuxtaponer raíces en el discurso sin que exista expresión alguna de las determinaciones puramente gramaticales, semánticas y discursivas operativas en éstas y otras muchas lenguas del mundo. También hemos visto que estas lenguas tienen una rica morfología derivativa y que por tanto no son lenguas sin morfología, como se suele decir a veces de forma totalmente errónea. En estas lenguas existen auténticas palabras con su estructura interna, tal como hemos podido comprobar prácticamente.

Tampoco se trata de lenguas monosilábicas ni de lenguas sin gramática. La gramática de las partículas chinas y vietnamitas es particularmente compleja y está llena de todo tipo de particularidades que se pueden explotar de maneras muy sutiles para denotar muy diversos matices sintácticos y semánticos. La multiplicidad de valores que encontramos, por ejemplo, en nuestro se la podemos comprobar también en partículas chinas como le o zhe o vietnamitas como mà o o làm.

Ciertamente, ni en chino ni en vietnamita los verbos se flexionan para persona, pero esto es debido al principio de la perspectiva que señalaba en la primera sección de este artículo. No existe coincidencia en los aspectos gramaticales que las lenguas señalan de modo explícito morfológicamente. Pero eso no quiere decir que las lenguas que no realizan morfológicamente esas categorías y funciones sintácticas no estén regidas por ellas. Sólo un análisis en profundidad de las lenguas que vaya más allá de lo observable a primera vista puede sacarnos de los errores derivados de apreciaciones superficiales normalmente impregnadas de ideología etnocentrista. 


\section{Una lengua incorporante no tan distinta del chino: el chucoto}

Examinemos ahora brevemente una lengua que parece estar en el extremo opuesto de las lenguas mal denominadas aislantes o monosilábicas. Esta lengua es el chucoto ${ }^{39}$, idioma incorporante y polisintético.

Esta lengua conoce la incorporación nominal y verbal ${ }^{40}$. El adjetivo, por ejemplo puede aparecer incorporado en el sustantivo, tal como lo muestra la palabra ottëpoigëqai 'lanza de madera' compuesta de poig 'lanza' y ott 'madera' (Dunn 1999: 170). Pueden incorporarse varios elementos al sustantivo, tal como vemos en el ejemplo siguiente (Skorik 1948: 58):

(26) Incorporación al sustantivo en chucoto

chawchywaënpëkllawol

chawchywa-ënpë-kllawol

nómada-viejo-hombre

'El anciano nómada'

El objeto directo puede aparecer incorporado en el verbo para formar holofrases como la siguiente (Dunn 1999: 225).

$$
\begin{aligned}
& \text { Holofrase en chucoto } \\
& \text { tëtlënnëmatg'at } \\
& \text { tëtlë-nnëmat_g'at } \\
& \text { puerta—cerrar-3pl. } \\
& \text { 'Han cerrado la puerta.' }
\end{aligned}
$$

Esta lengua admite incorporación múltiple. Dunn (1999: 233-234) menciona que hay una tradición de los chucotos para crear trabalenguas por medio de la incorporación múltiple. He aquí un trabalenguas de éstos:

(28) Trabalenguas chucoto

$$
\begin{aligned}
& \text { ngër'ow'arekengunengel'igëm } \\
& \text { ngër'o-w'are-kengu-nenge-l'-igëm } \\
& \text { tres-patas-bastón-herramienta-nominal- } 1^{\text {a }} \mathrm{sg} \text {, } \\
& \text { 'Tengo un bastón de tres patas.' }
\end{aligned}
$$

Observa Skorik (1948: 134) que las bases nominales incorporadas en el verbo chucoto simplemente caracterizan semánticamente al verbo sin que quepa hablar de nombre incorporado con función marcada de objeto, directo, indirecto o circunstancial. La situación que se obtiene así es similar a la que veíamos en chino y vietnamita en donde la relación de objeto directo, por ejemplo, no se expresa explícitamente sino sólo a través de la posición del nombre (palabra invariable) y el verbo.

39 Conocido también como chukchee, chukchỉ. Tenía unos doce mil quinientos hablantes en los años noventa, en la parte norte y sur de Chukotka. Pertenece a la familia chukoto-kamchadal.

40 Para el planteamiento de los problemas teóricos suscitados por la incorporación en chucoto debe consultarse Spencer (1995). 
Es bastante evidente que el chino es una lengua incorporante como el chucoto. Podemos comparar la palabra chucota tëtlënnëmatg'at 'han cerrado la puerta' con el chino 念书 niànshu 'estudiar, leer' compuesto de 念 niàn 'leer' y 书 shu 'libro'. Es claro que en niàns$h u$ hay un proceso de incorporación del sustantivo en el verbo muy similar, si no idéntico, al que se produce en chucoto, en el que el sustantivo incorporado $\mathbf{f} s h u$ 'libro' sirve para caracterizar la acción de leer sin hacer referencia a ningún libro concreto, cosa que es exactamente lo que ocurre cuando en chucoto se incorpora un sustantivo al verbo: se desatiende objeto implicado denotado por el nombre incorporado (Skorik, 1948: 116).

Curiosamente existe una palabra en chino que es paralela a la expresión chucota tëtlënnëmatg 'at 'han cerrado la puerta', pues en ella se incorpora puerta a cerrar. Se trata de la palabra 仃主 $\propto$ guanménzhûyi "ensimismamiento"41, que analizamos como sigue:

(29) Análisis de la palabra china con incorporación 关门主 X guanménzhîyi

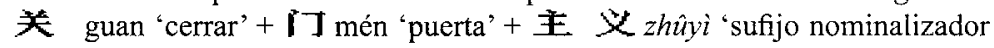

Está claro que, de modo similar al chucoto tëtlënnëmatg'at, la expresión china 门 guanmén 'cerrarpuerta' presenta un caso claro de incorporación nominal.

De hecho, si comparamos la expresión chucota tëtlënnëmatg'at 'han cerrado la puerta' con su versión china tamenguanlemén, que se suele transcribir como tamen (ellos) guan (cerrar) mén (puerta), veremos que chino y chucoto están mucho más cerca de to que la división tradicional entre lenguas aislantes e incorporantes nos hace ver.

\section{La utilización de la tipología morfológica para la evaluación de la complejidad de las lenguas: el caso de la supuesta simplicidad de la gramática de las lenguas criollas}

Recientemente ha resurgido la polémica de si las lenguas criollas son más simples o sencillas que las demás lenguas a causa del trabajo de McWhorter (2001). Voy a examinar los argumentos de este autor a la luz de las consideraciones precedentes y de las que haré sobre una lengua criolla concreta en la sección siguiente.

El primer argumento que da este autor es que no hay ninguna asunción en la lingüística moderna de la que se deduzca que todas las lenguas han de ser igualmente complejas. De hecho y, desde un punto de vista evolutivo, afirma que no hay mecanismo cognitivo o funcional alguno que explique que los cambios lingüísticos fortuitos producen siempre un resultado similar en cuanto a complejidad en todas las lenguas del mundo (McWhorter, 2001: 131).

Aquí McWhorter deja de tener en cuenta un dato crucial ${ }^{42}$; todas las lenguas conocidas satisfacen un requisito: son aprendibles en un período de tiempo similar por parte de las nuevas generaciones de hablantes. Una demostración irrefutable de que las lenguas tienen complejidades diferentes vendría dada por el hecho de que determinadas lenguas se adquie- 
ran por parte de los niños a los tres años y otras no se pudieran adquirir hasta los doce o veinte años ${ }^{43}$. Pero esto no se da. Todas las lenguas del mundo son naturalmente aprendibles del mismo modo y en un período de tiempo similar. Si, con todo, se sigue manteniendo que unas lenguas son más complejas que otras habría que demostrar que los niños que adquieren lenguas más simples hacen menos esfuerzo y tienen más tiempo para desarrollar otras aptitudes antes que los que tienen que adquirir lenguas más complejas, para los que esa mayor complejidad afectaría a la rapidez de desarrollo de otras aptitudes. Si esto no es así, es decir, si los niños que aprenden unas y otras lenguas son iguales en su desarrollo cognitivo, entonces hay que deducir que los niños que aprenden lenguas más complejas tienen mayores aptitudes o capacidades lingüísticas o de otro tipo que los que aprenden lenguas menos complejas. Ninguna de las dos explicaciones parecer estar en consonancia con lo que sabemos sobre estas cuestiones.

Por tanto, el argumento de la igual aprendibilidad de todas las lenguas del mundo conocidas lleva, si no se acepta, a suposiciones que contradicen nuestros conocimientos más elementales sobre cómo se adquieren las lenguas naturales.

McWhorter parte de la hipótesis de que milenios de cambio lingüístico han hecho que las lenguas más antiguas hayan adquirido una serie de rasgos inútiles que no están presentes en las lenguas surgidas más recientemente, como los criollos (2001: 132). Este razonamiento es disparatado porque, estrictamente hablando, las lenguas, por muy antiguas que sean, se transmiten de generación en generación como si fueran lenguas recién creadas, ya que los que las aprenden no tienen para nada en cuenta la historia centenaria o milenaria de esa lengua. Todas las lenguas actuales del mundo son, por tanto, nuevas. Todo lingüista sabe que las lenguas no van acumulando elementos de generación en generación. Esto se ve muy bien en el vocabulario. Nuevas generaciones añaden nuevo vocabulario al ya existente, pero se pierde mucho vocabulario antiguo que no pasa a las nuevas generaciones. En los demás niveles ocurre exactamente lo mismo. Una lengua no va acumulando marcadores gramaticales o tipos de construcciones sintácticas de generación en generación. Si lo hiciera, en efecto, cada siglo la lengua sería cada vez más compleja. Pero sabemos que no es así: el inglés moderno no tiene la gramática del anglosajón más la del inglés medio y la del inglés contemporáneo; el español no tiene la gramática del latín, más una gramática castellana adicional. Con el paso del tiempo desaparecen unos aspectos de la lengua y se sustituyen por otros. Esta es la razón por la no tiene el menor sentido la hipótesis fundamental de McWhorter ${ }^{44}$.

McWhorter utiliza para evaluar la complejidad de las lenguas cuatro criterios ${ }^{45}$ : complejidad del inventario fonológico, cantidad de reglas sintácticas, morfologización de distinciones semánticas y/o pragmáticas precisas (fine-grained) y existencia de flexión.

No voy a detenerme en el primer criterio porque este artículo examina sólo la cuestión morfológica. Sin embargo merece la pena decir que el recuento del número de fonemas

\footnotetext{
43 Me refiero aquí, por supuesto, al aprendizaje natural de la lengua oral y no al de la lengua escrita, que depende de la escuela y del aprendizaje controlado. Algunos sistemas de escritura más complejos como el chino pueden originar que la adquisición de la lengua escrita sea más larga o difícil.

44 En la misma dirección va la observación de DeGraff (2001:235) según la cual los hablantes no viven durante milenios. Si entendemos por lengua el conocimiento lingüístico de los hablantes, entonces la idea de que una lengua tiene siglos de antigüedad es absurda.

45 McWhorter (2001: 135-137).
} 
marcados dentro de un sistema fonológico no es en modo alguno suficiente para determinar la complejidad, dado que es sabido que no todos los fonemas de un sistema tienen el mismo rendimiento funcional y es más sabido aún que los fonemas más marcados en las lenguas son los que menos rendimiento funcional tienen. Por otro lado, en una lengua en la que no hay determinados fonemas marcados puede ocurrir que ciertos fonemas de configuración compleja tengan más rendimiento funcional que los correspondientes fonemas de una lengua en cuyo sistema fonológico hay fonemas muy marcados (ausentes en la primera) con escaso rendimiento funcional. El criterio tal como lo utiliza McWhorter es de una simplicidad e ingenuidad tales que ningún fonólogo competente podría tomárselo en serio ${ }^{46}$.

El segundo criterio hace referencia al número de reglas sintácticas presentes en una lengua. Este criterio es aún menos fiable que el anterior. Es sabido que lingüistas de distintas escuelas teóricas proponen distinto número de reglas para los mismos fenómenos sintácticos. Por ejemplo, para muchos gramáticos en una oración como voy mañana se ha aplicado una regla de elisión del pronombre personal sujeto yo de modo que a partir de la oración yo voy mañana se obtiene voy mañana aplicando esta regla. Sin embargo, yo mismo he argüido ${ }^{47}$ que no existe tal regla de elisión, dado que la deíxis verbal de persona de la forma verbal voy hace referencia al participante agente del suceso denotado. Prácticamente, respecto de la casi totalidad de reglas gramaticales que se han propuesto, hay análisis alternativos en los que o no existen esas reglas o en los que varias reglas distintas se reducen a una sola. Todavía no se ha determinado, por lo que conozco, cuántas reglas gramaticales tiene, por ejemplo, el inglés, una de las lenguas más investigadas del mundo actual: ¿ciento veinte? ¿cuatrocientas cuarenta? ¿mil doscientas? Sobre esta base tan indeterminada tiene poco sentido utilizar el criterio de la cantidad de reglas sintácticas de una lengua, ni siquiera del mismo inglés.

El tercer criterio hace referencia a la morfologización de distinciones semántico-pragmáticas más precisas o finas (fine-grained) en una lengua que en otra. Según McWhorter la clasificación verbal, típica de algunas lenguas indígenas de norteamérica, en la que hay afijos verbales que expresan tipos de objetos según su forma o textura, hace que estas lenguas sean más complejas que otras que no tienen esa clasificación verbal. Ahora bien, como he mostrado en otro lugar ${ }^{48}$, el hecho de que una lengua no tenga clasificación verbal no significa que no tenga una clasificación morfológica nominal similar.

Por otro lado, si no se especifica o determina qué se entiende exactamente por distinciones más finas, este criterio será de utilización arbitraria: depende de lo que se entienda en cada caso por distinción semántica y/o pragmática más fina o precisa. No tengo conocimiento de ningún criterio estrictamente lingüístico para colocar los morfemas en una escala de finura o precisión semántico-prágmática. Al comparar el clítico español se con el clítico búlgaro equivalente se deberíamos ser capaces de determinar cuál hace distinciones semántico-pragmáticas más finas. Pero ¿qué criterios utilizar para llevar a cabo esto? McWhorter no da ninguno, ¿cómo espera entonces que sus observaciones al respecto sean tomadas en serio?

46 La idea de que la aparente simplicidad paradigmática puede incrementar la complejidad fonotáctica originada por los alófonos es descartada a priori por McWhorter en la nota 7 de su trabajo. Precisamente este argumento es desarrollado por Moreno Cabrera (2000b: 119-127).

47 Moreno Cabrera (2000a: 462-470 y 2001: 112-115).

48 Moreno Cabrera (2000b: 106-109). 
El cuarto y último criterio es el que más nos interesa aquí y hace referencia a la existencia de flexión. La idea es muy simple: las lenguas que tienen flexión son más complejas que las que no la tienen. Aquí vuelve a surgir la idea decimonónica propuesta por Humboldt de que las lenguas con flexión son las más complejas y elaboradas. En su excelente contestación al artículo de McWhorter, DeGraff (2001) muestra cómo esta propuesta está imbuida del neodarwinismo lingüístico decimonónico tal como fue popularizado por Schleicher ${ }^{49}$.

McWhorter compara, para demostrar cómo se aplican sus criterios, la lengua caucásica dido con la lengua criolla saramacano. Del hecho de que la primera tiene 42 fonemas y la segunda 25, de que la primera tiene concordancia de clase nominal y la segunda no, de que la primera presenta suplencia léxica y la segunda no, de que la primera tiene muchos (large number) morfemas derivativos y la segunda solo tiene dos, de que la primera tiene dos órdenes distintos de oraciones interrogativas y la segunda sólo uno y de que la primera conoce en el pasado un morfema evidencial y la segunda no lo tiene, deduce nuestro autor que la gramática del saramacano es más simple que la del dido.

Pero este proceder es absolutamente impresentable desde un punto de vista lingüístico, ya que de ningún modo se tienen en cuenta todos los aspectos de las dos lenguas que pueden ser relevantes para determinar la complejidad de su gramática; se eligen unos pocos: los necesarios para demostrar la idea preconcebida que se quiere probar. Habría que presentar una descripción mínimamente completa y de parecida profundidad de las gramáticas de ambas lenguas. Aun si admitiéramos los criterios de complejidad utilizados por el autor, que hemos visto que son totalmente infundados, sólo podríamos deducir que el saramacano es más sencillo que el dido respecto de esos elementos, pero en modo alguno podemos deducir que la gramática del saramacano es más simple que la del dido. ¿Es que podemos derivar toda la gramática de ambas lenguas a partir de esos seis criterios? Es evidente que no.

Pero el delirio de McWhorter llega aún más lejos dado que afirma explícitamente que sus conclusiones sobre el saramacano se pueden aplicar a muchas otras lenguas criollas ${ }^{50}$, entre las que se encuentra el annobonés, que examinaremos en la sección siguiente. Si acabamos de razonar que esos seis rasgos lingüísticos utilizados no sirven ni siquiera para caracterizar toda la gramática del saramacano, a fortiori las conclusiones sobre la simplicidad de la gramática de esa lengua criolla no se pueden extrapolar a las de otras lenguas criollas.

En su artículo, McWhorter toma nota de la similitud entre muchas lenguas criollas y lenguas de Asia oriental como las sino-tibetanas. Se trata de ambos casos de lenguas muy analíticas en las que las determinaciones gramaticales se expresan mediante perífrasis en las que intervienen diversos elementos léxicos o de significado primariamente léxico. McWhorter intenta demostrar, utilizando los mismos criterios que antes, que esas lenguas sino-tibetanas son más complejas, sin embargo, que las lenguas criollas. Compara este autor la lengua tibeto-birmana lahu con el saramacano respecto de los criterios propuestos y en todos los casos llega a la conclusión de que, respecto de dichos criterios, el lahu está más elaborado y es más complejo que el saramacano. En la comparación McWhorter dice, sin

49 Dice concretamente: "McWhorter tacitly assumes the Schleicherian dogma whereby linguistic typology must, at all costs, include a genealogically and structurally well defined class of simplest grammars." (Degraff, 200 I: 223).

50 Concretamente al surinamés, enyuka, neomelanesio, bislamá, santotomense, principense, annobonés, angolar, negroholandés, malayo baba y papia kristán, entre otros. 
demostrar, cosas tan disparatadas como que el lahu tiene más verbos gramaticalizados que el saramacano y que muchas de sus funciones son "más específicas y más profundamente abstractas que las del saramacano" $" 51$.

Es bastante difícil compaginar ambos criterios: si una función es más específica difícilmente se ve cómo puede ser más abstracta, dado que son dos propiedades contradictorias. En general McWhorter dice que los verbos gramaticalizados en lahu presentan "un mayor grado de extensión metafórica que los del saramacano, y una tendencia hacia una subdivisión más precisa el espacio semántico" ${ }^{\prime 52}$. Para apoyar esta afirmación dice McWhorter que en lahu el verbo là se utiliza como marcador benefactivo sólo para la primera y segunda persona, mientras que en saramacano $k \dot{b}$ 'venir' se usa como marcador para todas las personas. Sin embargo, de aquí y de los tres ejemplos más que pone el autor, no se puede deducir que la gramática del lahu tenga globalmente un mayor grado de refinamiento semántico que la del saramacano, porque ello supone que toda la gramática de ambas lenguas se comporta igual que lo que indican esos ejemplos. Pero es sabido que ninguna lengua natural presenta una uniformidad total en todos los rincones de su gramática y que por tanto no se pueden hacen generalizaciones de este tipo.

Por ejemplo, del hecho de que la conjunción eta tenga más usos en vasco que la conjunción $y$ en español no se puede deducir que la gramática del vasco es más compleja que la del español. Tampoco se puede deducir de que el pronombre español se tenga más usos que el correspondiente pronombre basco bere burua, que la gramática del español es más compleja que la del vasco ${ }^{53}$.

También McWhorter hace referencia al inglés, lengua muy analítica y en muchos aspectos muy similar a las lenguas criollas ${ }^{54}$, para hacerlo inmediatamente de gramática más compleja que la de las lenguas criollas y la de las lenguas sino-tibetanas. Este autor afirma cosas tan disparatadas al respecto como la siguiente:

La sutil diferencia que mantenida en inglés entre el futuro will y el futuro going to es otro rasgo que da una manifestación sutil y gramaticalizada a una distinción que no existe ni en lahu ni en otras muchas lenguas (McWhorter, 2001: 149) ${ }^{55}$

Como observa DeGraff (2001: 283), podemos dar para cualquier lengua natural una lista de rasgos ad-hoc que tiene esa lengua y que no tienen las demás, por lo que este tipo de razonamiento es una falacia cuando se quiere usar para demostrar que una gramática es más simple que otra. Por ejemplo, en chino, lengua sino-tibetana como el lahu, existe una

51 "...with many of their functions being more specific and more deeply abstract than those in Saramaccan." (McWhorter 2001: 147)

52 “...exhibits a greater degree of metaphorical extension than Saramaccan's, and a tendency toward finer subdivision of semantic space." (McWhorter, 2001: 148)

53 Y eso suponiendo que ambas afirmaciones son ciertas, cosa que habría que demostrar cientificamente.

54 Según McArthur (1998: 176) el inglés ha experimentado tres procesos de hibridación lingüistica a partir del contacto entre el noruego antiguo (danés) y el anglo entre los siglos noveno y undécimo; a partir del contacto con el francés normando entre los siglos once y trece; y a partir del siglo dieciséis en adelante con el influjo masivo de vocabulario latino y griego sobre el estrato superior estandarizador del inglés.

55 "The subtle distinction maintained in English between the will future an the going to future is another feature which gives fine-grained and grammaticalized manifestation to a distinction in Lahu as well as a great many other languages." (McWhorter, 2001: 149) 
partícula oracional modal 了 le que indica cambio de estado y decisión o determinación tajante ${ }^{56}$. Es posible que no exista en inglés una partícula que indique exactamente esas dos cosas. Pero de ese hecho en modo alguno estamos autorizados a deducir que la gramática del chino es más compleja que la del inglés.

El principio de la perspectiva al que aludí en la primera sección es aquí determinante: las propiedades lingüísticas gramaticalizadas en una lengua son diferentes de las gramaticalizadas en otra y en este aspecto no hay dos lenguas exactamente iguales, es decir, que gramaticalicen o expresen morfológicamente exactamente las mismas propiedades o funciones. Por ello este tipo de argumentación no sirve para establecer criterios de complejidad en las gramáticas de las lenguas.

Es particularmente importante para el presente artículo la observación hecha por Hagège (2001: 172-173) según la cual este tipo de comparaciones se hace desde la perspectiva de la lengua escrita y no de la lengua hablada. Al hacerlo así, se pierden mecanismos fundamentales para la estructuración morfosintáctica de las lenguas, como la entonación. En todas las lenguas hay medios entonativos de expresar determinadas categorías y funciones gramaticales. Por ejemplo, en español se puede formar una oración interrogativa confirmativa mediante la expresión a que (A que no lo sabe todavia) o mediante la entonación ( ¿No lo sabe todavía?). Ambas formas están igualmente gramaticalizadas. La entonación no se ve en la escritura pero es una marca tan auténtica como una expresión o particula oracional. ¿Podemos estar seguros de que una lengua no marca explícitamente mediante la entonación una categoría que en otra lengua se marca mediante un morfema? No podemos estarlo hasta que no estudiemos la entonación seriamente.

Hay una conclusión inmediata que merece la pena resaltar: las lenguas criollas no son lenguas especiales distintas de las demás. No existe un tipo lingüístico criollo. P. Muysken, uno de los especialistas mundialmente reputados dentro del estudio de las lenguas criollas, concluye, después de examinar si las lenguas criollas son o no un tipo especial de lenguas:

Para concluir, la suposición de que las lenguas criollas son parecidas, simples y mixtas está lejos de no ser problemática. La noción misma de lengua criolla, desde el punto de vista lingǘstico, tiende a desaparecer si se observa de cerca: lo que tenemos es, simplemente, una lengua (Muysken, 1988: 364).

Otros autores mantienen exactamente esta postura:

No hay una clase estructuralmente denominada criollos definible sobre una base tipológica: en otras palabras, las lenguas criollas no pueden ser tratadas como diferentes sincrónicamente de cualquier otra lengua (Ansaldo y Matthews, 2001: 311 ) $^{57}$.

Con todo, es necesario dar una explicación al hecho de que la mayor parte de las lenguas criollas presentan unos rasgos característicos tales como la ausencia de flexión morfológica, o el predominio de las construcciones verbales auxiliares para indicar tiempo, 
aspecto, modo. Conviene ser conscientes de que esta tendencia a la expresión analítica no es en realidad característica de las lenguas criollas dado que, por ejemplo, si observamos el cambio del latín a las lenguas romances o del inglés antiguo o anglosajón al inglés moderno observamos exactamente la misma tendencia: pérdida de la flexión y predominio de las construcciones analíticas. Por ejemplo, la flexión de caso latina se sustituye en español y en las demás lenguas romances, por perífrasis con preposición.

Se sabe ya desde hace mucho tiempo en lingüística que no todos los rasgos gramaticales tienen el mismo status: unos son marcados y otros son no marcados. Por ejemplo, el número dual es marcado frente al plural. Esto significa que en el curso del cambio lingüístico una lengua puede perder el número dual y conservar el plural; sin embargo lo contrario es mucho más marcado y, por tanto, mucho menos frecuente. La determinación de los rasgos marcados y no marcados explica no sólo la diferente frecuencia de aparición de determinadas estructuras morfosintácticas en las lenguas en sincronía, sino también el diferente comportamiento diacrónico o histórico de dichas estructuras ${ }^{58}$.

Hagège (1982: 151-152), utilizando una metáfora genética, ha propuesto denominar dominantes a las características gramaticales no marcadas y recesivas a las características gramaticales marcadas ${ }^{59}$. Según Hagège los sabires ayudan a identificar los rasgos gramaticales recesivos de modo indirecto: son aquellos que se pierden en las formas de comunicación parciales de urgencia que son los sabires o pidgins. Las lenguas criollas, presentan en principio un predominio de rasgos dominantes sencillamente porque surgen exactamente mediante los mismos mecanismos históricos que han hecho que el inglés o el español hayan perdido la mayor parte de la flexión de las lenguas de las que proceden. La diferencia es que estos cambios, debido al contacto, se producen de modo acelerado.

A resultas de lo anterior, encontramos fácilmente una explicación de por qué las lenguas criollas se parecen tanto a muchas otras lenguas no consideradas criollas como por ejemplo a las lenguas sino-tibetanas ${ }^{60}$. Tanto unas como otras han experimentado procesos diacrónicos análogos y, por consiguiente, muestran una configuración parecida. Consiguientemente, no existe un tipo lingüístico criollo distinto de los de las demás ienguas; las lenguas criollas difieren de las demás lenguas sólo en las circunstancias históricas en las que surgen y, como no todas las lenguas criollas han pasado por exactamente las mismas circunstancias históricas, no podemos establecer generalizaciones que abarquen todas ellas justificando así la postulación de un grupo o categoría especial de lenguas criollas.

\section{La estructura morfológica de un criollo de base portuguesa: el annobonés}

Voy a examinar brevemente la estructura del criollo de base portuguesa annobonés, según la descripción de A. Zamora (2002). El annobonés es una lengua criolla hablada en la isła de Annobón, situada en el Golfo de Guinea cerca de la isla de Bioko y que constituye una provincia de Guinea Ecuatorial ${ }^{61}$. La base léxica de esta lengua lo constituye el portu-

\footnotetext{
58 El capitulo IV de Croft (1990) es una excelente panorámica de la teoria de la marcación en la linguiística tipológica.

59 T. Milewski (1973: 181-183) ya se refirió a rasgos lingüísticos recesivos y expansivos.

60 Como notan Ansaldo, U. y S. J. Matthews (2001).

61 Para un esbozo de la situación lingüística de Annobón en los años ochenta (véase de Granda 1985a).
} 
gués, con aportaciones del sabir inglés de Bioko ${ }^{62}$, del español ${ }^{63}$ y de un sustrato africano de origen bantú y kua ${ }^{64}$.

En su exposición de la morfología annobonesa, Zamora nos da ejemplos de la existencia en esta lengua de una estructuración morfológica de las palabras. Por ejemplo, yisjansá 'descansar' consta del prefijo derivativo yis- más la raíz jansá; livilament 'u 'libranza' consta de la raíz livilá más el sufijo derivativo -ment'u.

Nota Zamora la existencia de tres formas de los pronombres personales plurales: una masculina, otra femenina y otra epicena ${ }^{65}$.

\section{Tabla 2}

Tres formas de los pronombres personales plurales del annobonés

\begin{tabular}{|l|c|c|c|}
\hline pronombre & masculino & femenino & epiceno \\
\hline $1^{\circ} \mathrm{pl}$. & nóstulu & nóstola & nóstele \\
\hline $2^{\circ} \mathrm{pl}$ & vóstulu & vóstula & vóstele \\
\hline
\end{tabular}

Además existe un pronombre personal indefinido de tercera persona, similar al francés on: es el pronombre impersonal $a$, que podemos ver en una oración como la siguiente $a$ chiali offia 'se le acusó de brujería'.

Los determinantes aparecen en muchos casos fusionados morfológicamente con el sustantivo: ômã 'la mano', opè 'el pie' ônũa 'la luna'.

Además encontramos en annobonés diversos determinantes como el pluralizador $n \tilde{a}$ 'los/las', el indefinido $\tilde{a}$ 'un' y el pluralizador indefinido zuguã 'unos/unas'.

El annobonés conoce la categoría léxica de adjetivo que, como el sustantivo, conserva restos de género gramatical. Es precisamente en los adjetivos deverbales donde encontramos esa retención de la marca morfológica de género: ganadôl 'ganador' frente a ganadôl'a 'ganadora', jôlêdôl 'corredor' frente a jôlêdôl'a 'corredora'. La concordancia de género en el adjetivo la vemos en ejemplos como los siguientes:

(30) Concordancia de género en annobonés

a. Malà sa uã mosa fồmôz'a. 'María es una mujer hermosa.'

b. Filip sa ã masebu fômôz'ô. 'Juan es un muchacho hermoso.'

En el adjetivo hay una gran abundancia de sufijos que modifican su significado; por ejemplo, intensivos. He aquí unos ejemplos ciatados por Zamora (2002)

(31) Sufijos adjetivales intensivos en annobonés
a. chiut' $u$ 'bajo / corto'
cúutucunucun 'cortísimo'
b. baanc'u 'blanco'
baáncupepepep 'bláquísimo' 


$$
\begin{aligned}
& \text { c. pi 'verde (no maduro) } \\
& \text { d. } \sec ^{\prime} u \text { 'seco' }
\end{aligned}
$$

pijalajal 'verdísimo' sécujôlôjòl 'reseco'

Los verbos también pueden presentar esta sufijación intensiva como en: ventávivivi (del verbo ventá 'marchar' o 'ir a gran velocidad'), jôlếguidiguid (del verbo jôlế 'correr') 'correr a gran velocidad'.

Hay un fenómeno muy interesante en esta lengua consistente en la inserción del sustantivo determinado numeralmente con adjetivos numerales superiores a diez entre las unidades y las decenas. Por ejemplo, ã deixi cueli cu ôt'u 'dieciocho cucharas', cuya traducción literal es 'diez cucharas con ocho; o cent púluvu cu nov' $i$ 'ciento nueve pulpos'.

En esta lengua encontramos un morfema negativo discontinuo similar al del francés; se trata de na...f'a como en mosa sai na sa mosa gaavif'a 'Esa mujer no es una buena mujer'.

Dentro del ámbito del verbo, también hay morfología derivativa. El verbo conoce la voz pasiva, que es perifrástica como en portugués y español, y los aspectos perfectivo e imperfectivo. En cuanto al tiempo, se diferencia una forma presente (Él sajácumi 'come'), pasada ( $\hat{E} l$ cumi 'comió'), antepresente ( $\hat{E} l a ́$ cumi 'comió') y futuro ( $\hat{E} l$ sajécumi 'comerá'). También hay una forma subjuntiva.

Se encuentran formas verbales no personales, como el infinitivo, el participio y gerundio. En esta lengua hay verbos irregulares.

Hay preposiciones creadas a partir de expresiones portuguesas tales como la preposición bátoja 'hasta' procedente de vair tocar 'va a tocar' o dajant'u 'por' procedente de da cuantu.

Éstas son unas breves pinceladas de algunas de las características gramaticales del annobonés. No hay nada que haga pensar que la gramática del annobonés es más sencilla que la del portugués, porque, de hecho, hay mucho de la gramática del portugués en el annobonés. Desde luego, sería muy poco justificable decir que el annobonés es un portugués simplificado. Vemos que algunas características del portugués se pierden, pero hay otras que el portugués no tiene, algunas de las cuales hemos enumerado antes.

En general, puede decirse que las gramáticas de las lenguas criollas no se crean de nuevo, sino sobre la base de la gramática de una o varias de las lenguas que les sirven de base o punto de partida y que aquellas gramáticas no son una simplificación, depauperación o degeneración de éstas, sino una tansformación más o menos radical de las mismas de acuerdo con las leyes lingüísticas que son comunes a todas las lenguas, dado que de una lengua natural más se trata.

La falsa idea de que las gramáticas de las lenguas criollas son más sencillas o simples parte sin duda de una doble causa: no se han estudiado las lenguas criollas tan a fondo como las lenguas que les sirven de base $\mathrm{y}$, por tanto, no se han podido notar muchos aspectos sutiles y complejos de estas lenguas y, por otro lado, muchos de esos aspectos gramaticales se consideran simplemente copiados de una o varias de las lenguas de partida, por lo que se niega adscribir a las lenguas criollas aspectos complejos que las definen en sí mismas como sistemas lingüísticos, independientemente de su origen. Se podría decir, por ejemplo, que las formas temporales y modales verbales españolas están copiadas de las del latín; pero en realidad no es así, esas formas verbales son del español y definen la lengua española con sus peculiaridades aunque en última instancia procedan de nuestra lengua madre. 


\section{La utilización de la tipología morfológica para la determinación de la antigüedad de las lenguas: crítica de la lítico-lingüística}

En su, por lo demás interesante, obra sobre la prehistoria lingüística de Europa, M. Alinei (1996) dedica un capítulo a la indagación de las relaciones entre del desarrollo tecnológico y el lingüístico en la prehistoria ${ }^{66}$. En él, propone poner en relación directa los tres tipos de lenguas de la clasificación decimonónica: es decir, los tipos aislante, aglutinante y flexivo con tres tipos de instrumentos del paleolítico: los cantos trabajados (choppers), las lascas (flake tools) y las bifaces (hand-axes). Alinei recoge algunos datos arqueológicos según los cuales en Asia oriental encontramos la industria de los cantos trabajados, en Europa occidental, África septentrional y Asia occidental tenemos las bifaces y en Europa oriental y Asia central tenemos las lascas rudimentarias. Pues bien, según nuestro autor, esta repartición geográfica de las industruias líticas del paleolítico coincide con la distribución geográfica de los tres tipos de lengua. Las lenguas aislantes se concentran en Asia sudoriental, las lenguas flexivas ocupan más o menos las mismas zonas que aquellas en las que se encuentran las bifaces y las lenguas aglutinantes se encuentran precisamente en las áreas de las lascas: europa nororiental (filo urálico) y en Asia septentrional y central (filos urálico y altaico).

A partir de ahí, Alinei propone una correlación lítico-lingüística (Alinei, 1996: 457ss) consistente en la postulación de un estadio aislante primitivo correlacionado con la industria de los cantos trabajados: el canto tiene su correspondencia con el lexema simple de una lengua aislante. Por otra parte, las lascas se pueden relacionar, según Alinei, con los morfemas o lexemas gramaticales. Como las lascas son subproductos líticos que se obtienen de un núcleo, estamos ante un modelo material de la relación entre un lexema pleno y un morfema gramatical, que también es de núcleo y adyacente a ese núcleo. Esta industria de las lascas es puesta en correlación por Alinei con las lenguas aglutinantes, en las que se distingue perfectamente el núcleo léxico de las diversos morfemas gramaticales adosados a él. Por último las bifaces, que suponían un trabajo de talla de todo el núcleo lítico (ambas caras), se pueden poner en correlación con las lenguas flexivas. Esto se hace así porque, según Alinei, la elaboración del núcleo de la piedra de las bifaces abre el camino para la elaboración morfológica de los lexemas típica de las lenguas flexivas, en las que los morfemas quedan fusionados o íntimamente entreverados con el lexema. Sin embargo, en el caso de las lascas tenemos una separación neta entre el núcleo y las diversas esquirlas que se obtienen de él, cada una con su función correspondiente, siendo la única función de la base la de proveer de un número determinado de lascas.

Para apoyar esta osada correlación, Alinei nota las zonas en las que los cantos no son sustituidos por bifaces y en las que sí son sustituidos. Precisamente en las primeras (China, Birmania, Malasia, Hungría) predominan las lenguas aislantes o aglutinantes, mientras que en las segundas (Inglaterra, África Septentrional, Alemania oriental, Italia, Francia y Área adriática oriental) encontramos lenguas flexivas.

Voy a hacer unas consideraciones críticas a esta propuesta, creo que disparatada, de M. Alinei. 
Para poder evaluar la propuesta de Alinei es conveniente que demos un repaso, siquiera breve, a lo que algunos arqueológos y antropólogos han dicho sobre la correlación líticolingüística en general.

Th. Wyn $(1996)^{67}$ da un repaso a las propuestas que ha habido sobre la posible relación entre las herramientas del paleolíticos y el origen del lenguaje humano. Este autor propone que hay dos enfoques de esta cuestión. En un primer enfoque se relacionada la capacidad de construir herramientas con la capacidad lingüística y en un segundo enfoque se tienen en cuenta además las características de estos instrumentos ${ }^{68}$. En estas últimas propuestas son las bifaces las que tienen mayor protagonismo: su diseño y construcción se han puesto en correlación en diversas ocasiones con la complejidad de las reglas y funciones gramaticales.

Sin embargo, Wyn observa que, sobre la base del comportamiento prelingüistico de los niños y del comportamiento tecnológico de los adultos, no se puede fundamentar la existencia de una conexión clara y precisa entre el comportamiento tecnológico y el lingüístico. La regularidad de las primeras bifaces no parece correlacionarse con una conducta lingüística.

Wyn resalta tres puntos esenciales que ponen en cuestión la existencia de una relación directa entre los referidos comportamientos. En primer lugar, hay claros indicios de que el comportamiento tecnológico no está organizado a través de categorías léxicas; en segundo lugar la organización de las acciones no es equivalente a la del lenguaje: aquella parece tener carácter serial mientras que ésta tiene una organización jerárquica ${ }^{64}$; en tercer lugar, la organización del comportamiento tecnológico y lingüístico no parecen adquirirse de forma conjunta sino de forma separada. En diversas sociedades y culturas se ha podido comprobar que la adquisición de diversas habilidades tecnológicas de tipo manual no se llevan a cabo mediante instrucciones orales, sino mediante la observación directa de las actividades relevantes ${ }^{70}$.

La conclusión que extrae Wynnn de esto es que las habilidades para fabricar y usar instrumentos son diferentes de las habilidades lingüísticas y de hecho son más simples y evolutivamente anteriores:

Tools tell us little about language. [...]. Technology and language are not equivalent behaviours, and the connection between them is not simple. Modern technological behaviour is neither learned nor performed linguistically; and, even more important, prelinguistic behaviour includes language-like sequential patterns. These observations suggest that technological redundancy is simpler and probably earlier — phylogenetically as well as ontogenetically. As a consequence, we cannot conclude from the redundant patterns of bifaces at one million years ago, or later for that matter, tha any form of language was in use. (Wynn, 1996: 284)

\footnotetext{
67 Remito también a su trabajo anterior Wynn (1993).

68 Éste es precisamente el punto de vista que adopta Alinei.

69 Como observa Wyn esto no quiere decir que una acción pueda ser concebida jerárquicamente a través del lenguaje. Lo importante es que la organización inicial es claramente serial.

70 Téngase en cuenta que, por ejemplo, en los modernos manuales de instrucciones de los utensilios o muebles que han de ser montados antes de su uso, son muy frecuentes dibujos que indican cómo se han de montar esos utensilios o muebles. Normalmente utilizamos esos dibujos para realizar el trabajo de ensamblaje y nos resulta normalmente mucho más difícil hacerlo sólo sobre la base de instrucciones escritas.
} 
Otros autores como, en especial, Davidson y Noble (1993 y 1996), son aún más escépticos sobre la posibilidad de que las industrias líticas muestren las características lingüísticas del ser humano prehistórico. Según estos autores ${ }^{71}$, la elaboración de bifaces de formas análogas sería el resultado de acciones motoras aprendidas más que de intentos deliberados o planificados de reproducir una forma ideal; además, en la interpretación de estos autores, los homínidos no planificaban estrategias de fabricación de herramientas, sino que se acomodaban a las circunstancias locales según la disponibilidad de materiales y las necesidades ${ }^{72}$. En general, estos autores, concluyen que hay pocos signos de un comportamiento que requiriese necesariamente el tipo de previsión y planificación que atribuimos al uso del lenguaje. Esto autores consideran que el primer indicio indiscutible de este tipo de comportamiento, exclusivamente humano, es la llegada del ser humano a Australia hace unos 60.000 años, que requería una compleja planificación que incluyó la construcción de embarcaciones apropiadas. Sobre esta base opinan que el origen del comportamiento netamente humano hay que proponerlo entre hace cien y setenta mil años ${ }^{73}$.

Otros autores, sin embargo, sí opinan que es posible relacionar las industrias líticas prehistóricas con el origen del lenguaje humano moderno. Uno de ellos es Mellars (1998). Mellars opina que el surgimiento del lenguaje moderno puede estar relacionado con el período asociado al cambio conocido como revolución del Paleolítico superior, período (desde hace al menos 35-40.000 años) en el que se registran formas nuevas de instrumentos de piedra, el desarrollo de la talla del hueso y marfil, la existencia de cuentas de collar o pendientes y otros objetos de adomo personal, la existencia de los primeros instrumentos musicales y, sobre todo, los primeros signos inequívocos de arte. Estas características son contemporáneas precisamente con la aparición de las primeras poblaciones de seres humanos anatómicamente modernos y muestran para algunos estudiosos lo que se ha denominado como la revolución simbólica. ¿Qué implicaciones tiene esta revolución para la cuestión de los orígenes del lenguaje moderno? Mellars ${ }^{74}$ es de la opinión de que ningún arqueólogo, antropológo o psicólogo moderno puede poner en duda que la cultura del Paleolítico superior tiene que reflejar la existencia de patrones lingüísticos modernos entre las poblaciones más tempranas de humanos anatómicamente modernos.

Mellars ${ }^{75}$ nota que en este período del Paleolítico superior es cuando se produce más variación regional y tipológica (en Europa, fundamentalmente) en los diversos instrumentos líticos, que rompe claramente con la monotonía de períodos anteriores. Esta variación indica la existencia de fuertes tradiciones étnicas, culturales y sociales. Y aquí es precisamente donde cobra sentido el lenguaje humano moderno, ya que el lenguaje parece un medio necesario para mantener y transmitir las tradiciones culturales. Además, es un factor decisivo en la unificación de la cultura y comportamiento de grupos sociales específicos. Adicionalmente, el lenguaje es el medio más poderoso y eficaz para reforzar y mantener las diferenciaciones sociales entre distintos grupos étnicos. Por tanto, esta triple virtualidad del lenguaje humano moderno como instrumento de transmisión, unificación y diferenciación

71 Davidson y Noble (1996: 200).

72 Davidson y Noble (1996: 201).

73 Davidson y Noble (1996: 217).

74 Mellars (1998: 97).

75 Mellars (1998: 101). 
es la que hace verosímil que el surgimiento del lenguaje moderno se correlacionara con la revolución cultural del Paleolítico superior.

Sin embargo, Mellars llama la atención sobre lo que denomina la paradoja del Homo sapiens. Mientras que es evidente que ningún grupo humano o animal puede rendir por encima de sus posibilidades, también es igualmente evidente que un grupo puede rendir por debajo de sus posibilidades. De aquí se puede concluir que la ausencia de determinados patrones de conducta en un grupo no necesariamente es indicador de la falta de ciertas capacidades, sino más bien de que no se dan los factores adecuados para que dichas capacidades se manifiesten.

Muy importante en este sentido es la observación de Mellars (1998: 107) de que la falta de una tecnología avanzada del metal o de un conocimiento de matemáticas en las comunidades actuales de cazadores-recolectores, de ningún modo reflejan una ausencia de las capacidades cognitivas necesarias para estos comportamientos y menos aún una inferioridad cognitiva respecto de las sociedades industrializadas modernas. Por otro lado, tampoco es cierta la presunta simplicidad y uniformidad tecnológicas de las comunidades de cazadores-recolectores. En su repaso sobre las herramientas utilizadas por las comunidades de cazadores-recolectores, R. Torrence es particularmente claro:

To illustrate how optimal modelling of technology works on the macroscale, I will focus on the tools used by hunter-gatherers to obtain food. Considered on a global level, there is enormous variation among recent hunter-gatherers. Using concepts like more or less 'evolved' or 'advanced' to explain the differences is irrelevant. Instead one should try to understand why different choices were made. (Torrence, 2001: 75)

Las diferencias observadas ${ }^{76}$ en las herramientas no dependen de una supuesta mayor o menor evolución de los grupos implicados. El autor mencionado ${ }^{77}$ observa que la diversidad de las herramientas se incrementa cuando las herramientas para propósitos especiales son más efectivas para reducir los riesgos; por su parte, la complejidad de las herramientas se incrementa porque al añadir partes extra puede disminuirse el tiempo dedicado a la caza y aumentar la fiabilidad de la herramienta. Como ilustración de esto, aduce este estudioso el caso de la comunidad australiana de los aranda, que vive en un contexto con muchos recursos alternativos vegetales y animales y que usa muy pocos instrumentos y los costos de ello se compensan a través de la movilidad geográfica, frente al de la comunidad de los esquimales inuí que, al disponer de pocos recursos alimentarios (en el invierno dependen exclusivamente de las focas), han desarrollado una extensa gama de arpones, algunos de los cuales constan de hasta 26 piezas. En general, se ha observado que las herramientas usadas

\footnotetext{
76 Según Kuhn y Stiner (2001), este tipo de diversidad tecnológica se puede retrotraer al Paleolítico superior, en donde se asocia claramente con el Homo sapiens sapiens y, por consiguiente, las adaptaciones de los grupos actuales de cazadores-recolectores estaban ya establecidas hace unos 20.000 años y podrían proyectarse hasta hace unos 45.000 años, es decir en la primera etapa del Paleolítico superior. Los grupos de cazadores-recolectores del Paleolítico superior tardío respondían a los factores ecológicos y demográficos de forma similar a las sociedades cazadoras-recolectoras modernas. Esto puede interpretarse de diversas maneras; una de ellas es que el Homo sapiens sapiens del Paleolitico superior no era un hombre primitivo, sino un ser humano moderno, como quien ha escrito este artículo y el que lo están leyendo ahora.
}

77 Torrence (200!: 80$)$. 
para explotar los recursos acuáticos son habitualmente más complejas, dado que hay un mayor riesgo de perder la pieza.

Deducir de lo anterior que los aranda están menos evolucionados o desarrollados que los inuí no sería otra cosa que un disparate. Tampoco podemos, de forma mínimamente sensata, correlacionar la estructuras gramaticales de las lengua inuí y aranda con la complejidad de las herramientas usadas por las comunidades que las hablan.

$\mathrm{El}$ aranda $^{78}$ tiene un sistema consonántico con seis oclusivas (alveolar, postalveolar, interdental, palatal, dorsal y labial) y seis nasales de las mismas localizaciones que las oclusivas. Esta lengua también tiene diversas partículas clíticas, entre ellas, un clítico interrogativo $m a$; se trata, además, de una lengua morfológicamente ergativa que tiene una forma nominal ergativa, además de otros casos. Su conjugación verbal es regular, pues sólo hay una conjugación.

Por su parte el inuí ${ }^{79}$, tiene cuatro oclusivas y cuatro nasales, conoce también diversas partículas clíticas y casos nominales. También es una lengua morfológicamente ergativa y conoce igualmente una conjugación verbal regular.

Es claro que, a pesar de las semejanzas observadas, el aranda y el inuí son lenguas muy distintas, cada una tiene sus peculiaridades; pero parece extremadamente difícil, si no imposible, conectar la complejidad de una u otra lengua con la complejidad de los instrumentos de caza que tienen las comunidades implicadas. Parece más que evidente que el hecho de que el inuí sea una lengua incorporante y el aranda no (por lo menos a primera vista) nada tiene que ver con la complejidad de los arpones que usan los hablantes de la primera.

La correlación entre la complejidad de los instrumentos y la presunta complejidad de las gramáticas no está, pues, bien fundamentada en ninguno de los dos aspectos de la cuestión. Respecto del primer aspecto, parece que la complejidad de la herramienta no depende tanto del desarrollo o evolución como de las circunstancias de su uso: la complejidad de las herramientas que fabrique un ser capaz de realizar herramientas complejas depende de factores externos a esa capacidad y no de la capacidad misma, que sólo se manifestará en todo su potencial si las circunstancias así lo exigen. Respecto del segundo aspecto, hemos visto en las secciones anteriores que la tricotomía aislante, aglutinante y flexivo no demuestra la complejidad o simplicidad de los sistemas lingüísticos.

Con todo, hay un aspecto de la relación entre lengua y teconología que sí está bien establecido: se trata de la conexión entre los objetos y utensilios y las palabras que los designan. Igual que es esperable encontrar una palabra para lluvia o agua en todas las lenguas del mundo, dado que las comunidades humanas no pueden subsistir sin el líquido elemento o en alguna ocasión han estado en contacto con ese fenómeno meteorológico, también es razonable buscar palabras que denoten determinados objetos o utensilios artificiales o naturales elaborados en ellas. Mediante la reconstrucción del vocabulario común de las lenguas de una familia puede llegarse a determinar elementos de la cultura material de la comunidad que hablaba la lengua madre ancestral que dio origen a los idiomas de la familia estudiada. 
En este ámbito sí podemos encontrar algunos datos de interés relevantes para la líticolingüística. En su reconstrucción del vocabulario del macrofilo nostrático ${ }^{80}$, Dolgopolsky (1998: 26) llega a la conclusión de que no hay un núcleo de vocabulario reconstruible que pueda asociarse a una cultura neolítica ${ }^{81}$; sin embargo, sí pueden reconstruirse diversos términos relacionados con piedra, madera, piel, cuernos, diente, corteza y espina, lo que sugiere una cultura mesolítica o paleolítica. Por ejemplo, propone ${ }^{82}$ un término *chür con el significado de 'pedernal, cuchillo' reconstruible sobre la base de raíces afroasiáticas, altaicas y drávidas.

Sin embargo no podemos ir más allá de la correlación léxica en este terreno, ya que la estructura de la gramática de una lengua no es directamente relacionable con la estructura tecnológica, dado que las leyes de cambio gramatical son independientes de las leyes del cambio tecnológico (si es que las hay).

\section{Contra la interpretación evolucionista de la tipología morfológica clásica}

He dado argumentos en la sección anterior en contra de una interpretación evolucionista de los tres tipos lingüísticos en conjunción con una interpretación, también evolucionista, de la industria lítica prehistórica, poniendo en duda así a la denominada lítico-lingüística.

Sobre este tipo de interpretaciones evolutivas de las estructuras lingüísticas podemos argumentar utilizando lo que sabemos sobre cómo cambian las lenguas. Las lenguas actuales clasificadas como aislantes, aglutinantes y flexivas no son restos de estadios de la evolución del lenguaje humano. No hay forma de justificar lingüísticamente que el chino o el turco son residuos o restos lingüísticos de etapas pasadas de la evolución del lenguaje humano. El chino y el turco son dos lenguas que presentan todas las características típicas de una lengua humana moderna desarrollada. No cabe hacer, pues, una interpretación evolucionista de los tipos lingüísticos que encontramos en el mundo actual.

Lo anterior se hace tanto más evidente cuanto más estudiamos la historia lingüística interna de las lenguas. Si comparamos el anglosajón o inglés antiguo con el inglés moderno, caeremos enseguida en la cuenta de que el inglés es una lengua mucho más aislante que el anglosajón, que era una lengua claramenre flexiva. Lo mismo ocurre con el latin y el francés: el francés hablado es una lengua mucho más aislante que el latín, lengua típicamente flexiva. Tanto en el francés hablado como en el inglés no hay casi rastros de los casos nominales o de la flexión verbal de persona típicos tanto del anglosajón como del latín.

Para comprobar que esto es así veamos un ejemplo ilustrativo. En inglés antiguo, un adjetivo tenía una flexión de 48 formas distintas. Veamos la flexión del adjetivo trum 'firmes.

80 La hipótesis del macrofilo nostrático postula que existió una lengua ancestral, el nostrático, que dio origen a diversos filos lingüísticos tales como el indo-europeo, afro-asiático, kartuélico, urálico, altaico y drávida. Esto supone que lenguas como el griego (indo-europea), georgiano (kartuélica), finés (urálica), turco (altaica) y kanarés (drávida) estarian lejanamente emparentadas.

81 El vocabulario común de las lenguas indoeuropeas, muy rico en términos relacionados con la agricultura y la cerámica, sí puede asociarse, por el contrario, con una cultura neolítica (Dolgopolsky, 199: 26).

82 Dolgopolsky (1998: 65).

83 Quirk y Wrenn (1957: 31 y 33). 
Tabla 3

Flexión del adjetivo trum 'firme' en inglés antiguo

Declinación indefinida

\begin{tabular}{|l|l|l|l|}
\hline & masc. & neut. & fem. \\
\hline sg. nom. & trum & trum & trumu \\
\hline sg. acus. & trumne & trum & trume \\
\hline sg. gen. & trumes & trumes & trumre \\
\hline sg. dat. & trumum & trumum & trumre \\
\hline sg. instr. & trume & trume & trumre \\
\hline pl. nom./acus. & trume & trumu & truma \\
\hline pl.gen. & trumra & trumra & trumra \\
\hline pl. dat./instr. & trumum & trumum & trumum \\
\hline
\end{tabular}

Tabla 4

Declinación definida

\begin{tabular}{|l|l|l|l|}
\hline & masc. & neut. & \multicolumn{1}{|l|}{ fem. } \\
\hline sg. nom. & truma & trume & trume \\
\hline sg. acus. & truman & trume & truman \\
\hline sg. gen./dat./instr. & truman & truman & truman \\
\hline pl. nom./acus. & truman & truman & truman \\
\hline pl.gen. & trumra & trumra & trumra \\
\hline pl. dat./instr. & trumum & trumum & trumum \\
\hline
\end{tabular}

$\mathrm{Si}$, en este caso, descontamos las formas homófonas, las 48 que antes hemos mencionado se reducen a 13. Aún así, dado que en el inglés moderno el adjetivo no se flexiona ni para género ni para caso ni para número, tenemos una reducción de un mínimo de trece formas a una sola. Es decir, hemos pasado del tipo flexivo al tipo aislante, al menos en el caso del adjetivo.

Algo similar ha ocurrido con el verbo. Veamos la conjugación del verbo del inglés antiguo lufian 'amar's4.

(32) Conjugación del verbo del inglés antiguo lufian 'amar'

a. Presente:

b. Indicativo:

i) lufie 'amo'

ii) lufast 'amas'

iii) lufadh 'ama'

iv) lufiadh 'amamos/-áis/-an'
Pasado:

Indicativo:

lufode 'amaba'

lufodest 'amabas'

lufode 'amaba'

lufodon 'amábamos/ -áis/ -an' 
c. Subjuntivo:

i) lufie 'ame/-es/-e'

ii) lufien 'amemos/-éis/-en'
Subjuntivo:

lufode 'amara/-as/-a'

lufoden 'amáramos /-áis/ -an'

Estas doce formas (a las que podemos añadir dos más del imperativo) se reducen en inglés moderno a tres: love, loves y loved. Con ello tenemos de nuevo un acercamiento casi total a una morfología aislante.

Una cuestión distinta de esta es la que consiste en postular que, antes de adquirir el aspecto que ahora tienen, las lenguas humanas han ido pasando por diversas fases. Ahora bien, sin duda esas fases han de presentar unas lenguas distintas (quizás más sencillas) que las lenguas que conocemos actualmente $y$, dado que todas las lenguas humanas de que tenemos información suficiente tienen un nivel de complejidad similar, en cada una de esas fases esas lenguas ancestrales de las nuestras sí han de ser por definición esencialmente diferentes de las que conocemos en la actualidad. Por tanto, las lenguas humanas precursoras de las nuestras no sabemos cómo eran pero lo que sí está claro es que no eran como el chino o como el annobonés, que son idiomas humanos tan desarrollados como cualquiera otro.

\section{El chino, las lenguas criollas y los fundamentos lingüístico-culturales de la igualdad y dignidad de las lenguas}

Ya he aludido, al final de la sección quinta de este artículo, que se han encontrado muchas semejanzas en la estructura gramatical de las lenguas criollas y de algunas lenguas de Asia oriental como el chino o el vietnamita. Ansaldo y Matthews (2001: 318-321) analizan los siguientes dos paralelismos: falta de una morfología flexiva que en los criollos puede reducirse a un par de afijos flexivos, exactamente igual que lo que ocurre en chino, donde se han identificado dos afijos flexivos (los marcadores aspectuales le y $z h$ ) y la existencia de una morfología derivativa transparente y regular; a ello podemos añadir la existencia de la construcción polirremática, en la que los verbos desempeñan las funciones que en otras lenguas llevan a cabo las preposiciones y, en general, una estructura gramatical analítica en la que se expresan mediante perífrasis determinaciones gramaticales (aspectuales, temporales, modales) que en otras lenguas se expresan de modo sintético.

Pero aquí interesa resaltar el siguiente hecho. La lengua china escrita existía ya no más tarde del último cuarto del segundo milenio antes de Cristo ${ }^{85}$ en la China norcentral. Los primeros testimonios en escritura china datan del 1200 antes de Cristo. La lengua China es, pues, una de las más antiguamente atestiguadas de la Humanidad, junto con el griego, cuya variedad micénica está documentada también a finales del segundo milenio antes de Cristo. En el caso del chino, tenemos una lengua escrita que ha pervivido a lo largo de más de tres milenios y que ha estado asociada a una cultura también milenaria. Por consiguiente, la lengua china ha sido escrita desde hace al menos tres mil años. A lo largo de todo ese tiempo, la lengua ha ido cambiando hasta ofrecer las características que conocemos hoy en día y unas pocas de las cuales he puesto de manifiesto en la sección tercera del presente artículo.

Es realmente importante resaltar que las características gramaticales de una lengua con tanta tradición cultural detrás y con una larga historia como el chino, sean tan similares 
a las de lenguas con una historia mucho más corta y, por tanto, sin esa tradición cultural milenaria. Para mencionar la lengua criolla que he analizado, el annobonés, sabemos que la isla de Annobón fue descubierta en 1472 y que permaneció bajo dominio portugués hasta $1778^{86}$. Por tanto, en esos doscientos años debió formarse esa lengua. En total, la historia del annobonés no llega, pues, al medio siglo. Algo similar puede decirse de otras lenguas criollas: el haitiano, criollo de base francesa, se formó a partir de mediados del siglo XVII y hacia la primera mitad del siglo XVIII ya existía como tal criollo ${ }^{87}$; el papiamento se originó entre 1650 y 1700 en Curazao ${ }^{88}$.

Puede resultar sorprendente que lenguas que han surgido de forma muy rápida y en circunstancias culturales poco favorables, como las que han dado origen a las lenguas criollas, en las que interaccionan comunidades que no tienen lengua común y muchas veces en relaciones de sometimiento de una comunidad a otra, tengan unas características gramaticales muy similares a otras, como es el caso del chino, con una larga historia milenaria y con una tradición escrita muy antigua.

Creo que esto es una demostración muy clara de que las lenguas humanas se desarrollan con completa independencia del carácter favorable o desfavorable de las circunstancias culturales, políticas o económicas que determinan a las comunidades que las hablan. Como rasgo esencial y primario de toda comunidad humana, la lengua se desarrolla en todo su potencial sean cuales sean las condiciones que rodean a la sociedad que la utiliza; siempre, claro es, que se satisfagan unas condiciones mínimas que posibiliten la supervivencia de esa comunidad.

Precisamente este razonamiento pone de manifiesto la dignidad e igualdad esenciales de todas las lenguas humanas.

\section{Conclusión: en pro de la dignidad e igualdad de las lenguas}

He de empezar ésta última sección del artículo haciendo un compendio de todo lo que hemos ido viendo a lo largo de él.

En primer lugar, he notado que la clasificación de las lenguas en los tres tipos ya establecidos en el siglo XIX (lenguas aislantes, aglutinantes y flexivas), sigue hoy perviviendo en los manuales de lingüística. La interpretación de esta tricotomía en términos evolutivos, según la cual el tipo aislante está menos evolucionado que el flexivo, propuesta en el siglo XIX, no aparece explícitamente enunciada en los trabajos modernos sobre el tema. Sin embargo, eso no significa que esa interpretación no esté en el origen de algunos análisis modernos de la cuestión. De hecho, he mostrado que algunas de las ideas sobre la tipología lingüística actual están imbuidas de esta interpretación evolucionista de los tipos de lengua: sobre todo algunas de las que hacen referencia a la simplicidad de las lenguas criollas y a la antigüedad de las lenguas aislantes.

Una idea fundamental es que no hay compartimentos estancos en los que colocar a las lenguas. En algunos aspectos, unas lenguas parecen ser más analíticas que otras, pero ello no significa que esos calificativos puedan aplicarse a cada lengua en su totalidad. No tiene 
sentido hablar de lenguas analíticas frente a lenguas sintéticas; en todo caso, de lenguas con una morfología predominantemente analítica frente a lenguas con morfología predominantemente sintética; pero la morfología es sólo un aspecto de una lengua entre otros, quizás es el que más llame la atención al no lingüista, pero no es claramente el único ni el esencial.

Pero aun dentro de la compración estrictamente morfológica de las lenguas, he observado que no se comparan niveles análogos. En efecto, suelen compararse formas lingüísticas escritas de unas lenguas con formas lingüísticas orales de otras. La lengua escrita, como sabemos, es enormemente artificiosa y poco natural y sus segmentaciones y unidades no suelen coincidir casi nunca con las de la lengua hablada. La cuestión es que, como la mayoría de las lenguas del mundo ni se escriben ni se han escrito nunca, inevitablemente se introducen en las comparaciones formas lingüísticas de la lengua oral. El sesgo ideológico y etnocéntrico de este tipo de comparaciones salta inmediatamente a la vista cuando comprendemos que el desajuste es muy fácil de solucionar, comparando esas formas de la lengua hablada con formas habladas de las lenguas que se escriben. Como he propuesto en este artículo, no es lo mismo comparar el vasco etxea 'la casa' con el español la casa que con el español lacasa. El predominio de la lengua escrita en la base educativa de los propios lingüistas, hace que muchos vean en lacasa una fusión de dos elementos, cuando en realidad ocurre lo contrario: la expresión escrita la casa no es más que una separación ortográfica de una morfema. He mostrado que la eliminación de esta inadecuación debida a un prejuicio etnocentrista puede hacer que la comparación entre dos lenguas presuntamente de tipos diferentes, dé unos resultados muy distintos de los que habitualmente se citan.

En la sección tercera de este trabajo hemos examinado otro de los lugares comunes de la bibliografía divulgativa: el de que el chino y el vietnamita son lenguas aislantes y monosilábicas. Incluso un acercamiento superficial a la morfología de ambas lenguas nos hace ver inmediatamente que ni una ni otra lengua tienen esas supuestas características que se les adjudican. Ciertamente, la escritura china en su apariencia más inmediata es aislante; pero el sesgo hacia la lengua escrita vuelve a jugar aquí una mala pasada, dado que lo que hay que comparar no es la escritura china con las demás lenguas, sino la lengua china que, por desgracia, muchos identifican equivocadamente con la escritura. En la sección cuarta, he comparado el chino, lengua conceptuada como aislante, con una lengua que se halla en el otro extremo de la clasificación: el chucoto, lengua polisintética. De nuevo, muestro que un acercamiento menos sesgado a la comparación entre ambas lenguas da como resultado que, sin dejar de notar las notables diferencias entre ellas, existe en algunos aspectos una afinidad mucho mayor que la que se suele suponer.

La sección quinta de este trabajo es un examen de una propuesta reciente que intenta mostrar que la gramática de las lenguas criollas es más sencilla o menos compleja que la de las lenguas no criollas. En esa propuesta se argumenta que, en la corta historia de las lenguas criollas, no ha habido lugar para la formación de los 'adornos' o 'complejidades' más o menos gratuitas presentes en las lenguas con una historia mucho más antigua.

La conclusión que saco de la comparación entre las lenguas criollas y lenguas de una larga historia como el chino, y que expongo en la sección novena de este trabajo es exactamente la contraria: las lenguas criollas pueden manifestar las mismas 'excrecencias' o 'adornos' que las lenguas con una historia muy dilatada, por lo que la historia más o menos dilatada no afecta en absoluto a la esencia estructural de las lenguas. 
Los criterios que se utilizan en la propuesta que analizo en la sección quinta para demostrar la menor complejidad de las lenguas criollas, carecen de fundamento científico y se manejan de modo sesgado por una interpretación evolutiva de las diferencia tipológicas entre las lenguas, posibilitada por el uso de conceptos de dudoso carácter científico como el de finura o precisión gramaticales.

En la sección sexta analizo brevemente la estructura gramatical del annobonés, lengua criolla de base portuguesa, para comprobar que estamos ante una lengua natural absolutamente normal y corriente, que si clasificamos como criolla es sólo porque conocemos su historia, que es muy reciente y, por tanto, las circunstancias concretas en que surgió.

La sección séptima del presente artículo analiza detenidamente otra de las propuestas que se basan en una interpretación evolutiva de las diferencias tipológicas entre las lenguas, esta vez con una relación explícita con la evolución de la industria lítica en el Paleolítico, en lo que se ha denominado lítico-lingüística. Acudiendo a lo que nos dicen los especialistas en arqueología y antropología evolutiva interesados en el origen del lenguaje humano, he mostrado que no tiene fundamento alguno la puesta en conexión directa del desarrollo tecnológico con el cambio lingüístico interno y, por tanto, que carece de plausibilidad la supuesta relación entre los diversos tipos de utensilios líticos y los tres tipos de estructuras morfológicas (aislante, aglutinante y flexivo).

Lo anterior no obsta para que puedan extraerse conclusiones interesantes sobre las circunstancias sociales y tecnológicas de las comunidades a partir de los vocabularios de sus lenguas, que está en la base de diversas propuestas tentativas sobre la relación entre los datos arqueológicos y lingüísticos en lo que se ha denominado paleontologia lingüística aunque creo que la expresión arqueología lingüistica es más adecuada para este tipo de enfoques $^{89}$. En esa sección he puesto algunos ejemplos interesantes de los muchos que podrían aportarse.

En la sección octava hago explícita mi crítica a la interpretación evolucionista de las diferencias tipológicas entre las lenguas, heredada del siglo XIX, a través de unos pocos ejemplos ilustrativos. El hecho de que el cambio lingüístico haga que lenguas otrora flexivas pasen a ser aislantes o predominantemente aislantes, muestra fehacientemente que en modo alguno tiene sentido pensar que la estructuración denominada aislante es más primitiva o simple que la aglutinante o flexiva.

La sección novena del presente trabajo reflexiona a propósito de un hecho claramente ilustrativo de que la estructura de las lenguas humanas nada tiene que ver con un determinado desarrollo histórico, político, económico y cultural. Muchos autores han notado una serie de similitudes muy llamativas entre la estructura gramatical del chino y la de muchas lenguas criollas. Precisamente, el chino es una de las lenguas escritas más antiguamente atestiguadas de la Humanidad y está asociada a una cultura milenaria y gráfica de más de tres mil años de desarrollo; por su parte, las lenguas criollas mejor conocidas han surgido en un par de siglos o menos y no son portadoras de una cultura específica e idiosincrásica ancestral ni escrita.

Ante ejemplos como éstos hay tres respuestas posibles, dos de ellas absurdas. La primera consiste en decir que la lengua china ha ido degradándose progresivamente a lo largo de los siglos hasta simplificar considerablemente su gramática y convertirse en una lengua venida 
a menos, empobrecida e incapaz de expresar con precisión y solvencia los sentimientos y conocimientos humanos. Nadie que conozca la lengua china moderna puede mantener este razonamiento. Es una conclusión absurda. La segunda consiste en decir que los hablantes de las lenguas criollas han conseguido en pocos años un tipo de estructura lingüística que los chinos han tardado milenios en desarrollar, con lo cual estos hablantes estarían más evolucionados que los chinos. Es también una conclusión absurda, que sólo puede basarse en el racismo más ramplón. La tercera respuesta consiste en decir que el chino, el haitiano o el annobonés son lenguas naturales humanas con todas las características esenciales que definen una lengua humana y con otras no esenciales pero que caracterizan la individualidad e idiosincrasia particular de cada una de ellas como idiomas propios de una comunidad humana. Esta respuesta no sólo no es absurda sino que es la única que es capaz de dar cuenta de los hechos sin necesidad de usar supuestos ideológicos de carácter etnocéntrico o racista.

\section{Referencias bibliográficas}

Abraham, W. (1974): Diccionario de Terminología Lingüistica Actual. Madrid, Gredos.

Alinei, M. (1996): Origini delle lingue d'Europa. Volume I. La Teoria della Continuità. Roma, II Mulino.

Ansaldo, U. y S. J. Matthews (2001): "Typical creoles and simple languages: the case of sinitic", Linguistics Typology 5-2/3, págs. 311-325.

Boltz, W. G. (1996): "Early Chinese Writing". En P. T. Daniels y W. Bright (eds.), The World's Writing Systems, Oxfird, Oxford University Press, págs. 191-199.

Cardona, G. R. (1988): Diccionario de Lingüistica. Barcelona, Ariel.

Chình, T. V. (1970): Structure de la langue vietnamienne. Librairie Orientaliste Paul Geuthner, París. Comrie, B. (1981): Language Universals and Typology. Syntax and Morphology. Oxford, Basil

Blackwell [vers. esp. Madrid, Gredos, 1988].

Croft, W. (1990): Typology and Universals. Cambridge, Cambridge University Press.

Davidson, I. y W. Noble (1993): "Tools and language in human evolution". En Gibson e Ingold (eds.): (1993), págs. 363-388.

Davidson, I. y W. Noble (1996): Human Evolution, Language and Mind. A psychological and archaeological inquiry. Cambridge, Cambridge University Press.

DeGraff, M. (2001): "On the origin of creoles: a Cartesian critique of Neo-Darwinian linguistics", Linguistic Typology, 5, 2/3, 2001, págs. 213-310.

Diebold, JR., A. R. (1987): "Linguistic ways to prehistory. En S. Nacev Skomal y E. C. Polomé (eds.) (1994): Proto-Indo-european: the archaeology of a linguistic problem. Studies in honor of Marija Gimbutas, Washington, Institute for the Study of Man, págs. 19-71.

Dixon, R. M. W. (1980): The Languages of Australia. Cambrige, Cambridge University Press.

Dolgopolsky, A. (1998): The Nostratic Macrofamily and Linguistic Palaeontology. Cambridge, McDonald Institute of Archaeological Research.

Dunn, M. J. (1999): A Grammar of Chukchi. (Tesis doctoral) Universidad Nacional de Australia. Gallardo Paúls, B. (2000): Evolución de Lenguas y Tipología. Valencia, Tirant Lo Blanch.

García Miguel, J. M. (2000): "Linguas do mundo e tipoloxía lingüística". En F. Ramallo, G. Rei-Doval y X. P. Rodríguez Yáñez (eds.): Manual de Ciencias da Linguaxe, Vigo, Edicións xerais de Galicia, 2000, págs. 173-220.

Gibson, K. R. y T. Ingold (eds.) (1993): Tools, Language and Cognition in Human Evolution. Cambridge, Cambridge University Press.

Granda, G. de (1985): Estudios de Linguiistica Afro-románica. Valladolid, Universidad de Valladolid. Granda, G. de (1985): "Sociolingüistica de un microespacio criollo portugués de África" (Annobon)". En Granda, G. de (1985), págs. 141-156. 
Granda, G. de (1985b): "Préstamos léxicos del Pidgin English en el criollo portugués de Annobon". En Granda, G. de (1985), págs. 207-217.

Granda, G. de (1985c): "Procesos de aculturación léxica en el criollo portugués de Annobon. En Granda, G. de (1985), págs. 181-192.

Granda, G. de (1985d): "Las retenciones léxicas africanas en el criollo portugués de Annobon y sus implicaciones sociohistóricas. En Granda, G. de (1985), págs. 195-206.

Greenberg, J. (1954): "A Quantitative approach to the morphological typology of language". En K. Denning y S. Kemmers (eds.): On Language. Selected writings of Jospeh Greenberg, Stanford, Stanford University Press, 1990, págs. 3-25.

Hagège, C. (1982): La estructura de las lenguas. Madrid, Gredos, 1987.

Hagège, C. (2001): "Creoles and the notion of simplicity in human languages", Linguistic Typology 5-2/3, págs. 167-175.

Her, Wan-I (2002): La formación de palabras en chino y en español, (tesis doctoral), Madrid, Universidad Complutense de Madrid.

Humboldt, W. von (1830-1835): "Über der Verschiedenheit des menschliches Sprachbaues und ihren Einfluss auf die gesitige Entwicklung des Menschengeschlechts". En W. von Humbdolt: Schriften zur Sprachphilosophie, Stuttgart, J. G. Cotta'sche Buchhandlung (1994), págs. 368-756.

Humboldt, W. von (1830 1835): Sobre la diversidad de la estructura del lenguaje humano y su infuencia sobre el desarrollo espiritual de la humanidad. Barcelona, Anthropos y MEC, 1990.

Kuhn, S. L. y M. C. Stiner (2001): "The antiquity of hunter-gatherers. En C. Panter-Brick, R. H. Layton y P. Rowley-Conwy (eds.) (2001), págs. 99-142.

Lefebvre, C. (1998): Creole Genesis and the Acquisition of Grammar. The case of Haitian creole. Cambridge, Cambridge University Press.

Mair, V. H. (1996): "Modern Chinese writing". En P. T. Daniels y W. Bright (eds.) The World's writing systems. Oxford, Oxford University Press (1996), págs. 200-208.

Marco, C. y L. Wan-Tang, (1988): Gramática de la Lengua China. Taipei, 2 vols.

Martinet. A. (1960): Elementos de Lingüistica General. Madrid, Gredos, 1974.

Martinet. A. (1985): Sintaxis General. Madrid, Gredos, 1987.

Martinet. A. (1989): Función y Dinámica de las lenguas. Madrid, Gredos, 1993.

McArthur, T. (1998): The English Languages. Cambridge, Cambridge University Press.

McWhorter, J. H. (2001): "The world's simplest grammars are creole grammars", Linguistic Typology, vol. 5-2/3, págs. 125-166.

Mellars, P. (1998): "Neanderthais, Modern Humans and the Archaeological Evidence for Language".

En N. G. Jablonski y L. C. Aiello (eds.): The Origin and Diversification of Language, Memoirs of the Californa Academy of Sciences $n^{\circ} 24$, San Francisco, California, págs. 89-116.

Milewski, T. (1973): Introduction to the Study of Language. La Haya. Mouton.

Moreno Cabrera, J. C (1987): Fundamentos de Sintaxis General. Madrid, Síntesis.

Moreno Cabrera, J. C. (1995): La Lingüistica Teórico-Tipológica. Madrid, Gredos.

Moreno Cabrera, J. C. (1997): Introducción a la Lingüistica. Enfoque tipológico y Universalista. Madrid, Síntesis.

Moreno Cabrera, J. C. (2000a): Curso Universitario de Lingüistica General. Tomo I. Teoria de la Gramática y Sintaxis General. Madrid, Síntesis.

Moreno Cabrera, J. C. (2000b): La Dignidad e Igualdad de las Lenguas. Crítica de la discriminación lingüistica. Madrid, Alianza.

Moreno Cabrera, J. C. (2001): "Verbo y oración: morfosintaxis interlingüística de la deíxis verbal de persona", Revista de Investigación Lingüística, IV, $\mathrm{n}^{\circ} 1$, págs. 109-156.

Morpurgo-Davies, A. (1975): "Language classification in the Nineteenth Century en T. A. Sebeok (ed.) (1975): Current Trends in Linguistics, 13. Historiography of Linguistics, La Haya, Mouton, págs. 607-706. 
Morpurgo-Davies, A. (1992): Nineteenth-Century Linguistics, vol. IV. En G. Lepschy (ed.): History of Linguistics, Londres, Longman.

Mounin, G. (dir) (1982): Diccionario de Lingüística. Barcelona, Labor.

Moure, T. (2001): Universales del lenguaje y linguo-diversidad. Barcelona, Ariel.

Munteanu, D. (1996): El papiamento, lengua criolla hispánica. Madrid, Gredos.

Muysken, P. (1988): “Son los criollos un tipo especial de lengua?”. En F. Newmeyer (comp.) (1991): Panorama de la Lingüística Moderna de la Universidad de Cambridge. II. Teoria lingüística: extensiones e implicaciones, Madrid, Visor, págs. 347-366.

Panter-Brick, C. R. H. Layton y P. Rowley-Conwy (eds.) (2001): Hunter-Gatherers. An Interdisciplinary Perspective. Cambridge University Press, Cambridge.

Quirk, R. y C. L. Wrenn (1957): An Old English Grammar. Londres, Routledge.

Sapir, E. (1921): Language. An introduction to the study of Speech. San Diego, Harcourt Brace \& Company.

Skorik, P. Y. (1948): Ocherki po sintaksisu chukotskogo yazîka. Inkorporatsiya [Esbozo de la sintaxis chucota. La Incorporación]. Leningrado.

Spencer, A. (1995): “Incorporation in Chukchi”, Language, 71, 3, págs. 439-489.

Torrence, R. (2001): "Hunter-gatherer technology: macro- and microscale approaches". En C. PanterBrick, R. H. Layton y P. Rowley-Conwy (eds.) (2001), págs. 73-98.

von Stechow, A. \& W. Geuder (1997): "Sind manche sprachen "präziser" als andere? Über morphologische kategorien und ihre interpretation". Vortrag im Studium Generale am 5. (1997), Tübingen. Universität Tübingen.

Whaley, L. J. (1997): Introduction to Typology. The Unity and diversity of language, Londres. SAGE.

Wynn, Th. G. (1993): "Layers of thinking in tool behavior". En Gibson e Ingold (eds.), págs. 389406.

Wynn, Th. G. (1996): "The evolution of tools and symbolic behaviour". En A. Lock y C. R. Peters (eds.) (1996): Handbook of Human Symbolic Evolution, Oxford, Clarendon Press, págs. 263287.

Zadoyenko, T. P. y H. Shuin (1986): Osnovy kitaiskogo yazyka [Fundamentos de lengua china]. Moscú, Nauka.

Zamora Segorbe, A. (2002): Gramática descriptiva del fá d'ambô. Madrid, Universidad Autónoma de Madrid. 